Illinois State University

ISU ReD: Research and eData

Theses and Dissertations

$7-9-2020$

\title{
The Dark Tetrad at Work: Examining the Effects of Bottom-Line \\ Mentality, Job Satisfaction, and Perceptions of Organizational Politics on Counterproductive Work Behavior
}

Ryan Barry

Illinois State University, ryan.t.barry@outlook.com

Follow this and additional works at: https://ir.library.illinoisstate.edu/etd

Part of the Psychology Commons

\section{Recommended Citation}

Barry, Ryan, "The Dark Tetrad at Work: Examining the Effects of Bottom-Line Mentality, Job Satisfaction, and Perceptions of Organizational Politics on Counterproductive Work Behavior" (2020). Theses and Dissertations. 1279.

https://ir.library.illinoisstate.edu/etd/1279

This Thesis is brought to you for free and open access by ISU ReD: Research and eData. It has been accepted for inclusion in Theses and Dissertations by an authorized administrator of ISU ReD: Research and eData. For more information, please contact ISUReD@ilstu.edu. 


\section{THE DARK TETRAD AT WORK: EXAMINING THE EFFECTS OF BOTTOM-LINE MENTALITY, JOB SATISFACTION, AND PERCEPTIONS OF ORGANIZATIONAL POLITICS ON COUNTERPRODUCTIVE WORK BEHAVIOR}

\section{RYAN BARRY}

68 Pages

Contemporary organizations often use personality measures when selecting new employees. Recent developments in the literature have shown that measures of the dark tetrad traits (narcissism, Machiavellianism, psychopathy, and sadism) provide additional benefits (e.g., incremental validity) over measures of normal personality (e.g., Big Five) in predicting counterproductive work behavior (CWB). The purpose for this study was to identify factors that may affect the positive relationship between higher levels the dark tetrad and CWB. We proposed that perceptions of supervisor's bottom-line mentality (their focus on prioritizing profits over other goals) serves as a moderator, whereas one's job satisfaction and perceptions of organizational politics (POP) serve as mediators of the relationships between the dark tetrad and CWB. Our results showed that BLM serves as a moderator of the relationship between sadism and CWB; job satisfaction partially mediated the link between all dark tetrad traits and CWB; and we identified POP as a partial mediator of the relationship between sadism and CWB. Implications for practice and research are discussed.

KEYWORDS: personality; dark tetrad; dark triad; counterproductive work behavior; personnel selection 
THE DARK TETRAD AT WORK: EXAMINING THE EFFECTS OF BOTTOM-LINE MENTALITY, JOB SATISFACTION, AND PERCEPTIONS OF ORGANIZATIONAL POLITICS ON COUNTERPRODUCTIVE WORK BEHAVIOR

\author{
RYAN BARRY
}

\begin{abstract}
A Thesis Submitted in Partial Fulfillment of the Requirements for the Degree of MASTER OF SCIENCE

Department of Psychology ILLINOIS STATE UNIVERSITY
\end{abstract}


Copyright 2020 Ryan Barry 
THE DARK TETRAD AT WORK: EXAMINING THE EFFECTS OF BOTTOM-LINE MENTALITY, JOB SATISFACTION, AND PERCEPTIONS OF ORGANIZATIONAL POLITICS ON COUNTERPRODUCTIVE WORK BEHAVIOR

\author{
RYAN BARRY
}

COMMITTEE MEMBERS:

Dan Ispas, Chair

Kimberly Schneider 


\section{CONTENTS}

Page

TABLES

FIGURES

CHAPTER I: THE PROBLEM AND ITS BACKGROUND 1

$\begin{array}{ll}\text { Statement of the Problem } & 1\end{array}$

$\begin{array}{ll}\text { Purpose } & 3\end{array}$

CHAPTER II: REVIEW OF THE RELEVANT LITERATURE 4

$\begin{array}{ll}\text { General Literature Review } & 4\end{array}$

The Dark Tetrad 4

Bottom-Line Mentality as a Moderator 9

$\begin{array}{ll}\text { Job Satisfaction as a Mediator } & 13\end{array}$

$\begin{array}{ll}\text { Perceptions of Organizational Politics as a Mediator } & 18\end{array}$

CHAPTER III: RESEARCH DESIGN 22

$\begin{array}{ll}\text { Method } & 22\end{array}$

$\begin{array}{ll}\text { Participants } & 22\end{array}$

$\begin{array}{ll}\text { Procedure } & 22\end{array}$

$\begin{array}{ll}\text { Measures } & 23\end{array}$

Dark Tetrad at Work (DTW) 23

Counterproductive Work Behavior (CWB) 23

Bottom Line Mentality (BLM) 23

$\begin{array}{ll}\text { Job Satisfaction } & 24\end{array}$

Perception of Organizational Politics (POP) 24 
$\begin{array}{ll}\text { Results } & 25\end{array}$

$\begin{array}{ll}\text { Data Cleaning } & 25\end{array}$

$\begin{array}{ll}\text { Descriptive Statistics } & 26\end{array}$

$\begin{array}{ll}\text { Hypotheses 1a-d } & 29\end{array}$

$\begin{array}{ll}\text { Hypotheses 2a-d } & 31\end{array}$

Hypotheses 3a-d 33

$\begin{array}{ll}\text { Hypothesis } 4 & 35\end{array}$

$\begin{array}{ll}\text { Post-Hoc Analysis } & 35\end{array}$

CHAPTER V: DISCUSSION OF RESULTS 37

$\begin{array}{ll}\text { Discussion } & 37\end{array}$

$\begin{array}{ll}\text { Summary of Results } & 37\end{array}$

$\begin{array}{ll}\text { Limitations and Future Research } & 40\end{array}$

Research Implications $\quad 41$

$\begin{array}{ll}\text { Practical Implications } & 42\end{array}$

$\begin{array}{ll}\text { Conclusion } & 44\end{array}$

$\begin{array}{ll}\text { REFERENCES } & 45\end{array}$

APPENDIX A: DARK TETRAD AT WORK SCALE 55

APPENDIX B: COUNTERPRODUCTIVE WORK BEHAVIOR - CHECKLIST 57

APPENDIX C: BOTTOM-LINE MENTALITY SCALE 58

APPENDIX D: JOB SATISFACTION SCALE

APPENDIX E: PERCEPTIONS OF ORGANIZATIONAL POLITICS SCALE 60

APPENDIX F: FIGURE 1 
APPENDIX G: FIGURE 2

APPENDIX H: FIGURE 3

APPENDIX I: FIGURE 4

APPENDIX J: TABLE 1

APPENDIX K: TABLE 2 


\section{TABLES}

Table

Page

1. Sample Demographics 27

2. Means, Standard Deviations, and Correlations of Study Variables 28

3. Hierarchical Regression Analysis Results Using CWB as the Criterion 32 


\section{FIGURES}

Figure $\quad$ Page

1. Conceptual Diagram Depicting Hypotheses 1a-d in Which Supervisor's BLM Moderates the Relation Between Each Dark Tetrad Trait and CWB

2. Conceptual Diagram Depicting Hypothesis 3a-d in Which Job Satisfaction Mediates the Relationships Between Each Dark Tetrad Trait and CWB

3. Conceptual Diagram Depicting Hypothesis 4 in Which POP Mediates the Relationship Between Sadism and CWB

4. Simple Slopes for Sadism predicting CWB at $-1,0$ and +1 SD of BLM 


\section{CHAPTER I: THE PROBLEM AND ITS BACKGROUND}

\section{Statement of the Problem}

Counterproductive work behaviors (CWB) are behaviors carried out by employees that harm an organization, its interests, or its members (Spector \& Fox, 2002). CWB is an umbrella construct conceptualized to represent similar but distinct constructs such as workplace aggression, retaliation, sabotage, theft, and withdrawal. Although these behaviors hurt the organization, its members, and/or its goals, they do not need to be intended to hurt others. An employee may engage in time theft (time that employees waste or spend not working during their scheduled work hours; Henle et al., 2010) with the intent to feel fairly compensated or make enough to pay a bill on time; the motive is not necessarily to hurt the organization (even if it does). Counterproductive behavior includes, but is not limited to monetary theft, time theft, purposely not following instructions, and physically or verbally hurting a coworker. Wells (1999) estimated that among U.S. organizations, the total cost of employee theft and fraud might be as high as $\$ 400$ billion dollars per year. A more conservative estimate given by Coffin (2003), suggested that employee theft and fraud costs U.S. organizations a total of $\$ 50$ billion dollars per year and accounts for $20 \%$ of failed businesses. The prevalence of these costs are not specific to the U.S either. A recent report from the Center of Retail Research (2010) estimated the global cost of theft for the retail industry is $\$ 38$ billion dollars. Whether the cost of these behaviors is $\$ 50$ billion or $\$ 400$ billion per year, future research on attenuating these costs is warranted.

An efficient way for organizations to mitigate the costs of CWB is to screen out those who are prone to engaging in these behaviors. In the past, researchers have tried predicting CWB using the Five-Factor Model (FFM; Costa \& McCrae, 1995). The FFM contains five higherorder personality factors (openness, conscientiousness, extraversion, agreeableness, and 
neuroticism) which were derived from creating clusters of lower-order individual traits that covary together. Research using the higher-order scores only predicted between $5 \%-10 \%$ of variance in CWB (Wu \& LeBreton, 2011). Hastings and O’Neil (2009) conducted a study using a facet-level (lower-order) measure of FFM traits to elucidate the relationship between personality and CWB. They were able to conclude that significant differences in lower-order facets were obscured when aggregated to represent the higher order factor. In other words, the relationship between personality and CWB was not fully captured using measures of the broad FFM traits. For example, neuroticism had an overall nonsignificant correlation with workplace deviance $(r=.12)$, but its facets of anger and immoderation were significant and did predict variation in workplace deviance. The cancellation effect from the facets that had nonsignificant negative correlations led the researchers to conclude that using the higher-order factor scores masked meaningful differences at the facet-level.

The limitations of using the global FFM traits in predicting CWB has led researchers to investigate more aberrant personality constructs as antecedents instead. There is a group of aberrant personality constructs that are commonly researched together known as the dark tetrad (Charbrol et al., 2009). The dark tetrad is a label for a cluster of four socially aversive personality traits (narcissism, psychopathy, Machiavellianism, and sadism) that can be found within a normal population. Those higher in narcissism have a tendency to have an inflated view of selfimportance and superiority (Paulhus \& Williams, 2002); People with trait psychopathy show a pattern of behavior with no remorse for ones actions, lack of empathy, grandiose sense of selfworth, and impulsivity (LeBreton et al., 2006, p.392); Those higher in Machiavellianism have a tendency to manipulate others for personal gain (Wilson et al., 1996); and those higher in sadism take pleasure in the pain and suffering of others (Buckels et al., 2012). O'Boyle et al. (2012) 
conducted a meta-analysis on studies linking the dark triad components (narcissism, psychopathy, and Machiavellianism) to CWB. They found that the dark triad explained $28 \%$ of variance in CWB, a significant increase from the 5\%-10\% explained by the FFM traits. There is less research on the link between the dark tetrad and CWB than on the dark triad and CWB, but the inclusion of sadism when predicting CWB has been shown to explain an additional $36 \%$ of variance (Tabatha Thibault, 2016). Furthermore, Thibault and Kelloway (2016) found that sadism moderated the relation between the dark triad and CWB. When sadism scores were low, the dark triad lost its significance in predicting CWB. These findings suggest that sadism is at least partially responsible for how the other dark traits manifest at work.

\section{Purpose}

The main purpose of this study is to investigate conditions in which the links between the dark tetrad and CWB are exacerbated or attenuated. This study will examine how supervisor's bottom-line mentality (i.e., refers to a narrow mindset of over-prioritizing the bottom-line outcome while ignoring competing priorities; Greenbaum et al., 2012), job satisfaction, and perceptions of organizational politics affect the positive link between the dark tetrad and CWB. Additionally, past research examining personality traits and work outcomes has largely excluded sadism, which provides an opportunity to identify new empirical links between sadism and other constructs relevant to organizational functioning. 


\section{CHAPTER II: REVIEW OF THE RELEVANT LITERATURE}

\section{General Literature Review}

\section{The Dark Tetrad}

The dark tetrad - an extension of the dark triad - is a cluster of four socially aversive personality traits that are often researched together. The original dark triad consisted only of narcissism, psychopathy, and Machiavellianism. Recently, researchers have suggested including sadism in the dark triad as well to constitute what is known as the 'dark tetrad' (Charbrol et al., 2009, Buckels et al., 2012). The dark tetrad traits have typically been researched in clinical contexts, but they also exist on a subclinical level. The clinical manifestations of these traits are characterized by an "all-encompassing pattern of aberrant and dysfunctional behavior, affect, and cognition that permeates multiple spheres of an individual's life on a daily basis" (LeBreton et al., 2006, p.389). In contrast, the subclinical variants are characterized by similar patterns in behavior, affect, and cognition, but they occur less frequently and on less extreme levels. In other words, the subclinical variants of these traits do not impede one's everyday functioning in order to be considered a personality disorder according to the fifth edition of the Diagnostic and Statistical Manual of Mental Disorders (DSM-5) criteria; as of now, only narcissism and psychopathy can manifest as severe personality disorders (American Psychiatric Association, 2013). Sadism used to be a personality disorder under the DSM-3 (American Psychiatric Association, 1987), but is no longer considered a clinical issue and is only classified in extreme cases as a paraphilic disorder (a psychiatric disorder classified by a persistent and intense pattern of atypical sexual arousal; American Psychiatric Association, 2013).

Subclinical narcissism is a construct that was defined in Raskin and Hall's (1979) research when they delineated subclinical from clinical narcissistic personalities. Based on the 
criteria in the DSM-3, its subclinical variant has facets of grandiosity, entitlement, dominance, and superiority. Those high in subclinical narcissism have an inflated sense of self-importance, a tendency to feel entitled, can be exploitative, and present themselves in an arrogant manner (DeShong et al., 2015; Paulhus \& Williams, 2002). The observable manifestations of these traits are very similar but can be differentiated based on the DSM- 5 criteria for personality disorders. Specifically, to be considered a clinical disorder one's personality needs to deviate from cultural norms, cause distress or problems with everyday functioning, and last over time (American Psychiatric Association, 2013). Those higher in subclinical narcissism pose a problem for organizations because of their inflated sense of self-worth. Those who feel they are not wellcompensated for their work might take it upon themselves to receive additional compensation elsewhere (e.g., theft).

Subclinical psychopathy shares some overlap with subclinical narcissism, but is conceptually distinct (LeBreton et al., 2006). Subclinical psychopathy is qualitatively characterized by the same patterns of behavior, affect, and cognition as clinical psychopathy. On the other hand, the subclinical variant of psychopathy is quantitatively different from the clinical version in terms of intensity and frequency of their behavior, affect, and cognitions. Both types of psychopathy are characterized by a lack of empathy or remorse, impulsive and irresponsible behavior, use of deception, a grandiose sense of the self-worth, and criminal tendencies. Those with clinical levels of psychopathy, however, are likely to engage in more severe antisocial behaviors (i.e., violent crimes) that lead to institutionalization; the frequency at which they engage in these behaviors makes it difficult to hide within a functioning society (LeBreton et al., 2006). Fortunately, it is estimated that those with clinical levels of psychopathy constitute less than $1 \%$ of the population. In contrast, those with only subclinical levels of psychopathy are 
estimated to constitute anywhere from 5-15\% of the population (LeBreton et al., 2006). Those higher in subclinical psychopathy engage in less extreme behaviors that, based on the variability in the estimate of their proportion within the general population, are harder to detect. Detecting those with subclinical psychopathy is difficult because they are not hesitant to lie, cheat, steal, manipulate, or hurt others (emotionally or physically) in order to reach their goals. The predator mindset of those higher in subclinical psychopathy makes them highly career oriented and likely to be operating within the higher levels of an organization (Boddy, 2015). At work, these people may engage in felonious activities such as petty theft, identity fraud, embezzlement, sexual harassment, or a number of other crimes and counterproductive behavior (Boddy, 2015; LeBreton et al. 2006).

Machiavellianism is "a strategy of social conduct that involves manipulating others for personal gain" (Wilson et al. 1996, p. 285). Those high in this trait are master manipulators and can also show a lack of empathy, lower levels of affect, a drive for achieving their own goals, and an aberrant view of morality (LeBreton et al. 2018; Wilson et al. 1996). Machiavellianism itself, even at the extreme end of the spectrum, is not considered to be a clinical personality disorder. However, Machiavellianism overlaps with the other dark triad traits a considerable amount. In a meta-analysis conducted by O'Boyle et al. (2012), interrelations between the three dark triad traits showed Machiavellianism covaries significantly with narcissism $(\mathrm{rc}=.30)$ and psychopathy $(\mathrm{rc}=.59)$. The large overlap between Machiavellianism and psychopathy is not theoretically surprising; those who are less susceptible to feeling the negative emotions that come with manipulating others would be prone to seeing it as a more effective means to achieve their goal. Unfortunately, that is not how Machiavellianism has been theoretically defined. Theoretically, Machiavellianism is distinct because one of the key behavioral manifestations of 
this trait is high impulse control, while in contrast a behavioral manifestation of psychopathy is behavioral disinhibition (Jones \& Paulhus, 2017). There is a surprising lack of research investigating this key distinction between Machiavellianism and psychopathy, but the existing empirical data can best be interpreted as these two traits being different sides of the same coin. This has even led some researchers to question why Machiavellianism is still considered as an independent trait within the dark triad and not subsumed under psychopathy (Miller, Hyatt, Maples-Keller, Carter, \& Lynam, 2017; Vize, Lynam, Collinson, \& Miller, 2018). Despite the conceptual ambiguity, these traits have shown to have different associations with job performance, CWB, and organizational citizenship behavior (O’Boyle et al., 2012; Thibault, 2016)

Sadism is the last trait in the tetrad and has been researched almost entirely on a clinical level. It was only recently that psychologists confirmed a subclinical variant of sadism termed “everyday sadism” (Buckels et al., 2012). Those higher in everyday sadism will take advantage of situations in which they can watch someone in pain or inflict that pain themselves.

Commonplace manifestations of everyday sadism would include seeking pleasure and enjoyment from the cruel behavior allowed in violent video games, harrowing films, crushing bugs, or seeking enjoyment from coworkers being punished (Buckels et al., 2013; Jones \& Paulhus, 2017). Together, all four traits (subclinical narcissism, subclinical psychopathy, Machiavellianism, and everyday sadism) compose the Dark Tetrad. From here on out, when mentioning any of the dark traits I will be referring to the subclinical variant unless otherwise specified.

Regarding the dark tetrad traits, there is a common tendency for manipulation or exploitation of others to achieve one's goals that is accompanied by a lack of concern for the 
consequences of those actions. From this viewpoint, it becomes clear how the dark tetrad is related to higher rates of CWB - those with predispositions to engage in abusive behavior, theft, withdrawal, or production deviance are likely to be those who have a blatant disregard for the well-being of others or their employers. For these reasons, research has slowly accumulated on the links between the dark tetrad and important work outcomes such as CWB (Thibault, 2016; Miller \& Stachowski, 2017; Fernández-del-Río, Ramos-Villagrasa, \& Barrada, 2020).

Since the proposal of the dark tetrad by Charbrol et al. (2009), a search on the database for "dark tetrad" returns 42 articles since 2009. Meanwhile, a search for "dark triad" returns 630 articles published since 2009. Although everyday sadism seems to be left out of most contemporary research on the dark traits, their structure, and manifestations, there have been indications of its importance and practicality in applied settings. The growing amount of literature on the practical applications of using the dark tetrad for selection purposes has not come without objections to including such measures in selection systems. Melson-Silimon et al. (2019) voiced their concern for including measures of the dark traits for selection purposes. Specifically, they warned practitioners against using measures of dark traits because it may lead to violations of the American with Disabilities Act (ADA, 1990). The ADA prohibits employers from using any sort of medical exam during the pre-employment process. Since narcissism, psychopathy, and sadism are present at the clinical level, one could make the legal argument that any measures of these traits should qualify as a medical examination. In response to MelsonSilimon et al. (2019), Reichin et al. (2019) argued that dark tetrad measures, in fact, are perfectly suited for selection purposes. Measures of dark traits cannot, and are not, used as medical examinations to identify personality disorders; therefore, measures of the dark tetrad do not meet the EEOC criteria for a psychological examination used to detect a medical disorder. Although 
job analysis would still be needed to show that such measures are job related, the current study aims to provide further empirical evidence for benefits of including 'dark' personality measures in organizational contexts.

In addition to these measures being well-suited for organizational contexts, they are highly useful in predicting CWB. In a study conducted by Thibault (2016), the dark tetrad predicted a significant portion of variance in CWB, workplace incivility, and bullying behaviors. Thibault (2016) used a new scale for measuring the dark tetrad that crafted each item to be applicable to organizational contexts - The Dark Tetrad at Work scale. The results indicated that her measure uniquely predicted variance in the previously mentioned criterion above and beyond the preexisting scales measuring the same traits. Furthermore, sadism appeared to predict variance in CWB above and beyond the other traits, making it arguably the most important trait in the tetrad when an organization is looking to prevent CWB. A past meta-analysis by O'Boyle et al. (2011) showed that the dark triad predicted a significant portion of variance in CWB (R2 = .28). Meanwhile, Thibault (2016) was able to explain $42-50 \%$ of variance by using The Dark Tetrad at Work scale. The current study aims to confirm the results from Thibault (2016) to provide more empirical support for the continued use of this scale in organizational settings and to utilize the DTW scale to further investigate sadism and its relation to other organizationally relevant constructs. Specifically, the current study intends to examine the roles of a supervisor's BLM, job satisfaction, and perceptions of organizational politics in the already establish link between the dark tetrad and CWB.

\section{Bottom-Line Mentality as a Moderator}

An organization's "bottom-line" historically refers to the bottom line of a financial report that shows the organization's profits or losses. A bottom-line mentality (BLM), as defined by 
Greenbaum et al. (2012), refers to a narrow mindset of over-prioritizing the bottom-line outcome while ignoring competing priorities (e.g., corporate responsibility, leadership, etc.). Greenbaum et al. (2012) proposed and tested a model that positively linked supervisor bottom-line mentality to social undermining. Social undermining is a "behavior intended to hinder, over time, the ability to establish and maintain positive interpersonal relationships, work-related success, and favorable reputation" (Duffy et al., 2002, p. 332). By definition, social undermining would be considered a specific form of CWB in which individuals with socially aversive personality traits are more likely to engage in.

Greenbaum et al. (2012) created a self-report measure of BLM. Since this study will be used to examine employee perceptions of their supervisor's BLM, items will need to be slightly revised to function as an other-report scale. To capture the employee's perception of their supervisor's BLM, items from Greenbaum et al. (2012) will be edited such that "I am solely concerned with meeting the bottom line" will be changed to "My supervisor is solely concerned with meeting the bottom line." This study is examining perceptions of supervisor's BLM because employee perceptions of the organizational environment provide a cognitive representation of the environment, give meaning to organizational events, and determine the actions needed to reach a desired outcome (Parker et al., 2003). Because it is the employee's perception of the environment that drives behavior, revising the BLM items from Greenbaum et al. (2012) to measure employees' perceptions of supervisor BLM should provide a more proximal measure of the construct.

Currently, there is no research that explains how an employee's perception of supervisor's BLM might affect the relation between the dark tetrad and CWB. To address this gap in the literature, I draw from Schneider's (1987) attraction-selection-attrition (ASA) 
framework and adopt a revised version of BLM scale developed by Greenbaum et al. (2012). The ASA framework proposes that the people that comprise an organization is largely determined by the three dynamic processes of attraction, selection, and attrition. The ASA model begins with attraction; people are drawn to organizations that they deem congruent with their own personal characteristics (e.g., personality, values, etc.). The next stage in the ASA cycle is the selection process. Organizations use formal and informal processes to select applicants who are desirable (i.e., employees that fit with the culture and can help reach organizational goals). Lastly, the attrition process occurs when an employee realizes that they do not fit in at the organization. When employees feel this sense of incongruence, or misfit, they are likely to leave the organization. In sum, employees that are similar in personality to each other and/or to management will generally stay in an organization, whereas those who are incongruent with the organization leave. The result is an organization composed of employees with similar characteristics. The ASA framework posits the homogeneity hypothesis - that personalities within an organization become more homogenous over time in regard to their personalities. Schneider et al. (1998) tested this hypothesis in a sample of 12,739 managers from 142 different organizations. They found a significant lack of within-organization variability in personality characteristics. Their results support the hypothesis that personalities within an organization are more homogeneous than would be expected from random chance alone. This empirical finding has since been replicated by numerous researchers across various organizational types and industries (Cooman et al. 2009; Satterwhite et al. 2009; Bradley-Geist \& Landis, 2012). The strong empirical support of the homogeneity hypothesis is germane to the current study because it demonstrates how it is the characteristics of the organizational members that ultimately create and drive its structure, culture, and processes. 
Given these findings, there should be a significant moderating effect of subordinates' perceptions of their supervisor BLM on the dark tetrad - CWB link (assessed with the employee as focal individual), such that it is exacerbated when perception of the supervisor's BLM is high. Those high in the dark tetrad trait(s) all have tendencies to exploit others in one way or another. In other words, they share a mentality in which they seem to only care about achieving a desired outcome, not whether it hurt or exploited another person in the process; hence, the dark triad is described as socially aversive. When supervisors have high levels of BLM, it can provide a safe haven for employees with dark personalities to engage in behaviors that would not elsewhere be tolerated (e.g., sabotage). One way in which this could occur is through preferential treatment. If the supervisor displays their belief that the ends justify the means (i.e., has a high BLM), as long as an employee makes the sale the supervisor will be pleased. Under these conditions, someone higher in narcissism might engage in time theft to satisfy their overinflated sense of worth; someone higher in Machiavellian might put the organization at legal risk by offering or soliciting bribes against company policy in order to meet their supervisor's bottom-line. In other words, the supervisor's BLM gives those with dark personalities a sense of immunity to consequences as long as they meet their financial goals. When supervisors lack this BLM, the ASA framework predicts employees with dark personalities would initially be less attracted to the organization. Furthermore, it posits that if they were attracted and selected into the organization, they would likely leave due to perceived incongruencies between their personal characteristics (e.g., personality, values) and those of their supervisor and the organization as a whole.

Hypothesis 1a: Perceptions of one's supervisor's bottom-line mentality moderates the relationship between narcissism and CWB, such that when supervisor's perceived BLM is stronger, the narcissism - CWB link will be strengthened. 
Hypothesis 1b: Perceptions of one's supervisor's bottom-line mentality moderates the relationship between psychopathy and CWB, such that when supervisor's perceived BLM is stronger the psychopathy - CWB link will be strengthened.

Hypothesis 1c: Perceptions of one's supervisor's bottom-line mentality moderates the relationship between Machiavellianism and CWB, such that when supervisor's perceived BLM is stronger the Machiavellianism - CWB link will be strengthened.

Hypothesis 1d: Perceptions of one's supervisor's bottom-line mentality moderates the relationship between sadism and CWB, such that when supervisor's perceived BLM is stronger the sadism - CWB link will be strengthened.

\section{Figure 1}

Conceptual Diagram Depicting Hypotheses la-d in Which Supervisor's BLM Moderates the Relation Between Each Dark Tetrad Trait and CWB

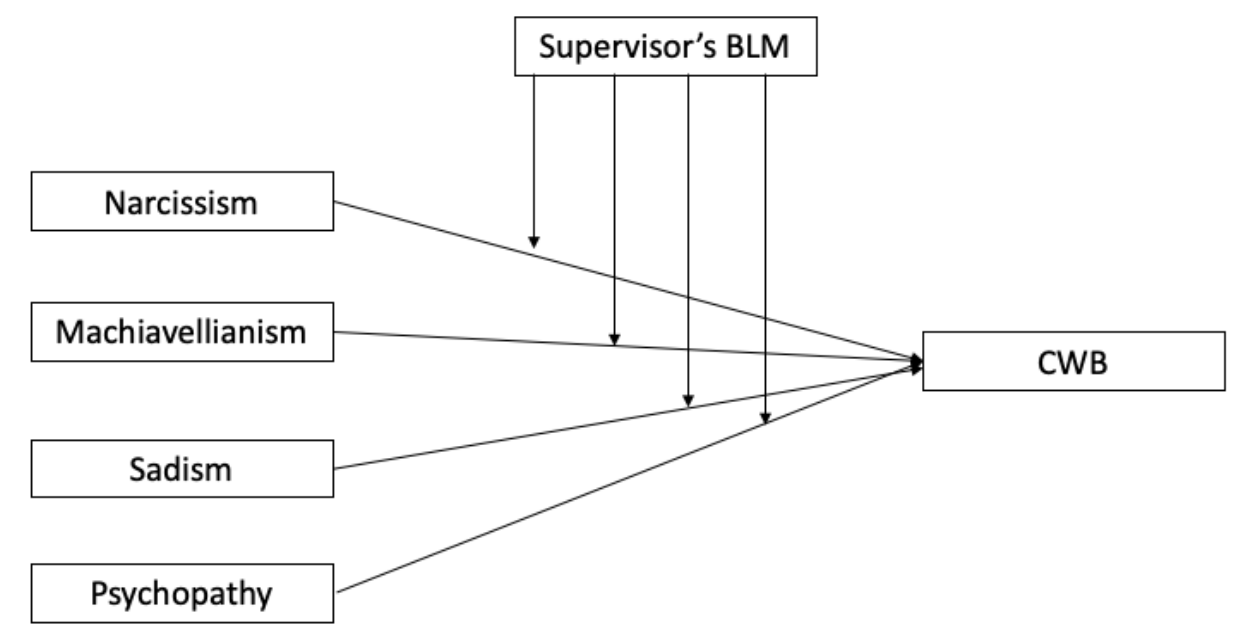

\section{Job Satisfaction as a Mediator}

Job satisfaction has been a dominant construct of interest in organizational research because it is linked to numerous work behaviors. Studies have linked job satisfaction with withdrawal behaviors, CWB, organizational citizenship behaviors (OCB), job performance, 
personality, and organizational commitment (Creed et al., 2007; Spector \& Fox, 2002; Spector \& Fox, 2005), but have not specifically examined the role of job satisfaction in the relations between the dark tetrad and CWB. The literature does offer some empirical examinations of the role of job satisfaction in the dark triad - CWB link, but such results have been inconclusive. Johnson et al. (2015) found that job satisfaction only significantly correlated with Machiavellianism ( $\mathrm{r}=-.15)$; Mathieu (2015) found narcissism did significantly correlate with job satisfaction ( $\mathrm{r}=-.16)$; and Boddy and Taplan (2016) found that psychopathy had a significant negative correlation with job satisfaction $(r=-.66)$. Despite inconsistencies in which traits significantly correlate with job satisfaction, there is empirical evidence that all three traits may have significant associations with job satisfaction. These discrepancies alone warrant further investigation, but there is also some indirect support linking the dark tetrad to job satisfaction. A study conducted by Buckels et al. (2012) was the first study to provide a behavioral confirmation that everyday sadism exists. The researchers recruited 71 undergraduate participants to complete the experimental task and measures of affect and sadism. For the experimental task, participants were told to choose among four tasks that would resemble realworld jobs. Three of these were control conditions (exterminator assistant, sanitation worker, and a cold weather worker) and one was the experimental condition (exterminator). Those who chose to be an exterminator were asked to crush bugs while their assistant handed them different cups of bugs. The bugs were personified by giving them names to make the task more similar to hurting a real person. They found that those who scored high on sadism preferred the exterminator condition over the other job choices. Those scoring higher on sadism also reported lower levels of pleasure from their job across all conditions than did nonsadists. Lastly, those 
scoring higher on sadism who chose not to kill bugs displayed the lowest levels of pleasure with their job, indicating that they may have regretted their choice to not kill bugs.

In a meta-analysis conducted by Connolly and Viswesvaran (2000), the authors found that job satisfaction significantly correlated with negative affect $(r=-.33)$. Since sadists reported lower levels of pleasure with their chosen jobs, it may also be related to lower levels of job satisfaction. Unfortunately, the paucity of research examining sadism at work has not examined its association with negative affect. There was, however, a study that showed job satisfaction is negatively related to Machiavellianism and psychopathy. Past research has also shown strong positive correlations between sadism and psychopathy $(r=.82)$, as well as between sadism and Machiavellianism ( $r=.44$; Thibault, 2016). The strong association among these constructs and the lower levels of pleasure reported in Buckels et al (2012) provide the initial rationale that sadism is also negatively related to job satisfaction.

Hypothesis 2a: There will be a negative correlation between narcissism and job satisfaction.

Hypothesis 2b: There will be a negative correlation between psychopathy and job satisfaction.

Hypothesis 2c: There will be a negative correlation between Machiavellianism and job satisfaction.

Hypothesis 2d: There will be a negative correlation between sadism and job satisfaction. In addition to support for the links between the dark tetrad facets and job satisfaction, there is ample empirical and theoretical support for 'path b' in the mediation model linking job satisfaction to CWB. Social exchange theory offers a promising interdisciplinary framework that supports the mediating role of job satisfaction. Social exchange theory, applied to an 
organizational setting, puts forth that employees build relationships with their employers based on principals of fair and reciprocal social exchanges. The employee offers his or her knowledge, skills, abilities, and other characteristics (KSAO) in exchange for monetary and socioemotional rewards (Settoon et al.,1996). One of the basic tenets of social exchange theory is that individuals form norms of reciprocity through these social exchanges (Cropanzano \& Mitchell, 2005; Gouldner, 1960). Over time, these quid pro quo exchanges can evolve into trusting and committed relationships. Once norms of reciprocity are formed, however, a perceived violation of these norms can lead to negative consequences. When an employee feels undervalued for their work (i.e., an imbalance in the social exchange between employee and employer) it leads to negative emotions like job dissatisfaction. Spector and Fox's (2005) stressor-emotion model of CWB can be utilized to understand how, under a social exchange perspective, job dissatisfaction leads to CWB. This model of CWB states that individuals appraise their environment for stressors. When environmental stimuli are perceived as a stressor, it can lead to negative emotions which may lead directly to CWB. More specifically, Spector and Fox (2005) theorized that personality traits can affect whether or not negative emotions occur upon the appraisal of a stressor. They predicted that narcissism, among other traits, would lead to more negative emotions and subsequently more CWB. Because part of the environment at work include relationships, social exchange theory offers a coherent theoretical conceptualization that can be applied through the stressor-emotion model of CWB.

Spector (2005) found negative correlations between job satisfaction and CWB. Specifically, job satisfaction is negatively correlated with CWB directed towards the organization (CWB-O; $r=-.45$ ) and CWB directed towards individual members of the organization (CWB-I; $r=-.14)$. This finding provides some initial support to investigate job 
satisfaction as a mechanism in which the dark tetrad manifest at work. In more recent research, the personality - CWB link has been shown to be at least partially mediated by job satisfaction (Bolton et al. 2010; Mount et al. 2006). Mount et al. (2006) examined job satisfaction as a mediator between the Big Five traits and CWB. They found strong correlations between job satisfaction and CWB-I $(r=.40)$ and CWB-O $(r=.41)$, but weaker indirect effects $(r=-.07$ and .23 , respectively). Creed et al. (2007) also reported that job satisfaction served as a mediator between individual dispositions and CWB. It is possible that these studies did not find stronger indirect effects because the Big Five traits are too broad to capture important dark aspects of personality. When using more narrow traits like those in the dark tetrad, these indirect effects should be exacerbated.

Hypothesis 3a: Job satisfaction mediates the relationship between narcissism and CWB. Hypothesis 3b: Job satisfaction mediates the relationship between psychopathy and CWB.

Hypothesis 3c: Job satisfaction mediates the relationship between Machiavellianism and CWB.

Hypothesis 3d: Job satisfaction mediates the relationship between sadism and CWB. 


\section{Figure 2}

Conceptual Diagram Depicting Hypothesis 3a-d in Which Job Satisfaction Mediates the Relationships Between Each Dark Tetrad Trait and CWB

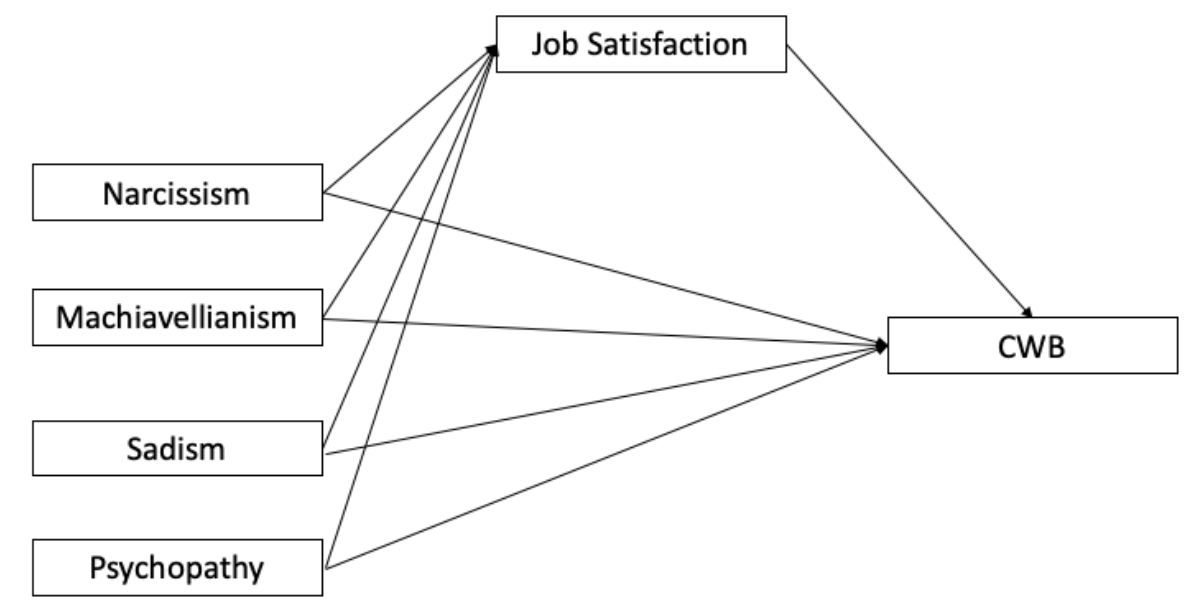

\section{Perceptions of Organizational Politics as a Mediator}

Perceptions of organizational politics (POP) are individuals' attributions of an event to "behaviors of self-serving intent and is defined as an individual's subjective evaluation about the extent to which the work environment is characterized by co-workers and supervisors who demonstrate such self-serving behavior.” (Ferris et al., 2000, p. 90). The first measure of POP that was validated in large samples was developed by Kacmar and Carlson (1997). Factor analysis revealed a three-factor structure which includes: (1) general political behavior, (2) go along and get ahead, and (3) pay and promotion. General political behavior is the degree to which an individual engages in self-serving behavior to reach a desired outcome (e.g., competing for limited organizational resources such as tickets, raises, office space, etc.). The second factor, go along and get ahead, refers to the degree to which an individual remains silent about other's political behavior in order to reap the rewards of that political agenda. Individuals go along with the political agenda for their own self-interest. For example, not speaking out against a wrongful 
termination in order to be promoted to the vacant position. Lastly, pay and promotion refers to how the organization uses policy to reward political behavior of an individual. Nye and Witt (1993) found evidence of discriminant validity with the Survey of Perceived Organizational Support (SPOS; Eisen-Berger et al., 1986). The SPOS was designed to measure the extent that an organization cares about their well-being and shows their appreciation for their employees. It had had strong negative relationship with the POP scale $(r=-.85)$ as predicted. Further evidence of validity comes from Kacmar and Carlson (1997). The POP scale was shown to be significantly related to nomologically related criterion such as job satisfaction $(r=-.62)$ and organizational commitment $(r=-.58)$. Additionally, they found that the three-factor structure showed superior fit over all other models in multiple samples using principal components analysis, exploratory factor analysis, and confirmatory factor analysis.

The original conceptualization of POP from Ferris et al. (2002) included both situational and personal characteristics that lead to the formation of individual perceptions. Specifically, he theorized that positive and negative affect are important antecedents to the formations of POP. Those higher in negative affect have a tendency to attribute work outcomes to negative stimuli in the external environment. Someone high in negative affect is more likely to perceive inequities in work outcomes as political as opposed to being due to one's own performance. As a result, these employees engage in CWB to make their perceptions of work outcomes more just. This phenomenon can be explained through social exchange theory. When an employee feels that there is an imbalance in the exchange of their work for organizational resources, they are motivated to seek out ways in which they can make the social exchange fair and reciprocal (Cropanzano \& Mitchell, 2005). Despite the original conceptualization, research examining 
antecedents to perceptions of politics have largely ignored the role of personality characteristics (Adams et al., 2008).

Adams et al. (2008) conducted the first study investigating trait affect as an antecedent to individual perceptions of politics. They found that negative affect was positively associated with higher levels of POP $(\beta=.24, \mathrm{p}<.01)$. Furthermore, two large meta-analyses have linked POP to negative organizational outcomes such as $\mathrm{CWB}$, turnover, low employee commitment, and low job satisfaction (Chang et al., 2009; Miller et al., 2008). These results indicate that POP may serve as a mediator between the dark tetrad and negative work outcomes. Other researchers have also hypothesized the mediating role of POP in the relation between dark personality traits and CWB. Baloch et al. (2017) identified POP as a mediator of the dark triad - CWB relationship and discovered that their mediated model explained a significant proportion of variance in CWB $\left(R_{2}=.76\right)$

To move the research forward, POP should be reexamined in relation to sadism and the dark tetrad. This study will be among the few designed to help researchers examine the link between sadism and POP, and to examine POP, the dark tetrad, and CWB together. In theory, the relationship between sadism and CWB should also be mediated by POP because past research has shown that trait negative affect is linked with higher levels of POP (Adams et al., 2008). Although the study conducted by Buckels et al. (2012) did not specifically measure negative affect, they report that those scoring higher on sadism often have significantly lower levels of positive emotions and engage in sadistic behavior in order to boost their positive emotions. Research on personality and perception has shown that emotions frequently influence perceptions (Ferris, 2002). For this reason, the effect of those scoring higher on sadism should influence them to perceive behavior as political more frequently than those with lower scores on 
sadism. When a someone higher in sadism feels the need for positive emotions they engage in harmful behaviors (i.e., CWB; Buckels et al., 2012). One way in which sadists can rationalize hurting a coworker or the organization is to label behavior as political. For example, employee A receives a fair and well-deserved promotion at work. When employee B (the sadist) finds out, they perceive this as political because by labeling it political behavior they have rationalized their desire to engage in retaliatory behavior (i.e., CWB) that will boost their positive emotions.

Hypothesis 4: POP mediates the positive relationship between sadism and CWB

\section{Figure 3}

Conceptual Diagram Depicting Hypothesis 4 in Which POP Mediates the Relationship Between Sadism and CWB

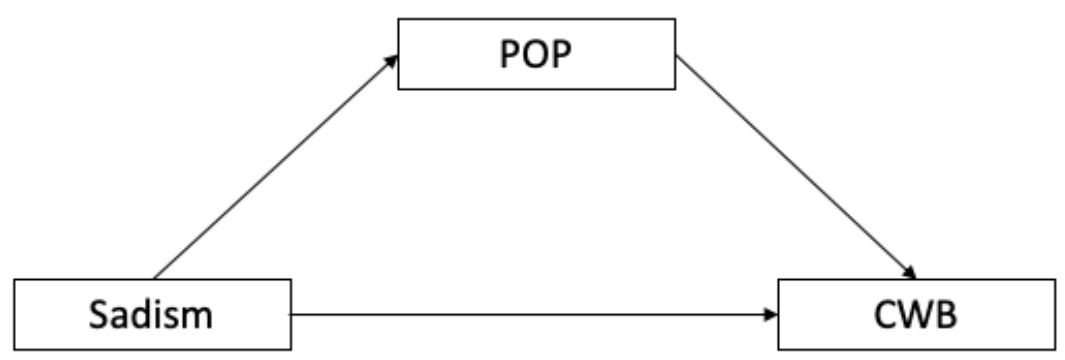




\section{CHAPTER III: RESEARCH DESIGN}

\section{Method}

\section{Participants}

Participants were recruited through online convenience sampling using Amazon MTurk. To be eligible for participation in this study, participants had to have worked in an organization (located within the U.S.) for more than 6 months and for more than 20 hours per week. Participants also needed to have a direct supervisor in order to capture their perceptions of their supervisor's BLM. These restrictions ensure that participants have been exposed to the organizational culture and have had the opportunity to engage in CWB. Based on the sample size recommendations from Fritz and MacKinnon (2006), a sample size of 468 participants should be enough to detect the smallest effect sizes with power $>.80$ when paired with a bias-corrected bootstrap mediation technique. This estimate represents the lower limit of participants needed to achieve .8 power, so this study aimed to recruit 500 participants to increase the likelihood of obtaining power of .80 .

\section{Procedure}

This study required that participants respond to an online Qualtrics survey through Amazon MTurk. The Qualtrics survey included the informed consent, the scales for each variable measured in this study, and demographic questions at the end. The link for the survey was included in the MTurk HIT along with a study description and a verification code that appeared upon completion. Those that were interested in participation were made aware of the purpose, benefits, and any risks of the study. The participants were also ensured that their data would remain confidential and that this study was not collecting data that could be used to identify an individual. Those who met the qualifications and gave their informed consent were 
then prompted with instructions to be as accurate and honest as possible. After completing the 99-item survey, the participants were given a debriefing statement and \$0.30 USD for their participation. Based on the data presented in Stritch et al. (2017), the average rate of pay is $\$ 2.00 /$ hour or $\$ 0.03$ per minute. Given the length of this survey, $\$ 0.30$ is above the average compensation for participation. After the predetermined sample size was reached, the survey was closed, and the data was analyzed according to the strategy for data analysis.

\section{Measures}

Dark Tetrad at Work (DTW). The DTW is a 22-item measure of the dark tetrad in organizational context. The measure contained six items measuring narcissism $(\alpha=.84)$, four measuring Machiavellianism $(\alpha=.87)$, six measuring psychopathy $(\alpha=.91)$, and six measuring sadism $(\alpha=.93)$. Participants responded to the items using a 5-point Likert scale $(1=$ strongly disagree, $5=$ strongly agree). An example item is "I love to watch my boss yell at my coworkers."

Counterproductive Work Behavior (CWB). CWB was measured using the Counterproductive Work Behavior - Checklist (CWB-C; Spector et al. 2006). This measure contains 10 -items that display excellent overall reliability $(\alpha=.90)$. An example item is: “Purposely wasted your employer's materials/supplies.” Participants recorded their responses using a 5-point frequency scale (1 never to 5 daily).

Bottom Line Mentality (BLM). BLM was measured using the 4-item scale developed by Greenbaum et al. (2012) that demonstrated excellent reliability $(\alpha=.94)$. This study asked each participant to respond to this scale in order to capture their perceptions of their supervisor's BLM. An example item includes: "[My supervisor] is solely concerned with meeting the bottom 
line." Participants recorded their responses on a 7-point Likert scale ranging from 1 (strongly disagree) to 7 (strongly agree).

Job Satisfaction. Job satisfaction was measured using the Brayfield and Rothe (1951) 5item job satisfaction scale that measured overall job satisfaction $(\alpha=.86)$. This scale was chosen for this study because the hypotheses focus on overall job satisfaction and made no predictions about variations at the facet level. Furthermore, this scale was well-suited for the study because it focuses more on satisfaction as an emotional response to work events more than other available scales (Moorman, 1994). Despite being created in 1951, item wording is still clear and easily understood for the target demographic of this study. An example item is: "I feel fairly well satisfied with my present job". Participants recorded their ratings on a 5-point Likert scale ranging from 1 (strongly disagree) to 5 (strongly agree). Two out of the five items were reverse coded.

Perception of Organizational Politics (POP). POP was measured using a 15-item scale developed by Kacmar and Carlson (1997). This scale has three subscales: (1) general political behavior, (2) go along to get ahead, and (3) pay and promotion policies. Example items include "People in this organization attempt to build themselves up by tearing others down", "Employees are encouraged to speak out frankly even when they are critical of well-established ideas", and "When it comes to pay raise and promotion decisions, policies are irrelevant", respectively. Scores from the three subscales were added together to represent an overall measure of one's perception of politics. The scale demonstrated good composite reliability as well $(\alpha=.88)$. 


\section{CHAPTER IV: RESULTS}

\section{Results}

\section{Data Cleaning}

The study was kept open for twenty-nine days on Amazon MTurk and collected data from a total of 577 participants (56 with missing data). The first step taken to clean the data was to filter out participants who finished the survey in under 198 seconds (avg. 2 seconds per item). This procedure was recommended by Huang et al. (2012) and Brower and Bowling (2017) as an effective method to mitigate the impact of careless responding in survey data. There were 86 participants who were removed due to completing the survey in under the minimum time cutoff. The remaining 491 participant sample was used to create a third sample in which 52 more participants who did not pass all four attention checks were filtered out. All hypothesis tests were conducted on each of these samples to inspect the results for discrepancies due to the data cleaning techniques. After filtering the full data set for duration, the only discrepancy was a change in which interaction term provided incremental validity in the hierarchical regression analysis (hypotheses 1a-d). This difference in results is not unexpected considering that of those finishing under the cutoff time, one participant finished in 8 seconds and over half finished in under 136 seconds (average pace of .72 seconds per item). Removing variability introduced from the low-quality data improved the regression line for the sadism*BLM interaction term; the improved regression line predicted the same moderating effect better than the previously significant narcissism*BLM interaction term. Applying the attention check filter to the sample already filtered for duration did not change any of the results in terms of significance. Since the attention checks did not change whether hypotheses would be rejected or not, we did not apply the attention check filter to the sample used for this study. The decision to not use attention 
checks to eliminate cases is also the current recommendation made by Qualtrics, as well as academic researchers, due to adverse effects they may have on the data (Vannette, 2016; Clifford \& Jerit, 2015).

\section{Descriptive Statistics}

The preliminary analyses led us to use the 491 participant sample that had been filtered for duration to complete the survey. The mean age for this sample was 40.23 years, with a standard deviation of 11.91. The age of the participants in this study covered a wide range of 1873 , with $50 \%$ of the sample falling between the ages of 31 and 49 . The sample was predominately white $(\mathrm{n}=367,74.7 \%)$, with 45 participants identifying as Black, 34 identifying as Asian, 9 identifying as Hispanic/Latino, 6 identifying as American Indian/Alaskan Native, 1 identifying as Native Hawaiian/Pacific Islander, and 2 identifying as Other/Multiracial. The sample was fairly even in terms of gender, with 259 females (52.7\%) and 205 males. Lastly, the mode for organizational tenure was 5+ years. A total of 41 participants had tenure of 6 months to 1 year; 130 had tenure of 1-3 years; 79 had tenure of 3-5 years; and $215(46.2 \%)$ had tenure of $5+$ years. Demographic data is also available in Table 1. Overall, with the exception of ethnicity, the sample is diverse in terms of age, gender, and tenure.

As shown in Table 2, all of the dark tetrad traits were significantly correlated. Narcissism correlated with Machiavellianism $(r(481)=.17, p<.001)$, psychopathy $(r(479)=.35, p<.001)$, and sadism $(r(479)=.37, p<.001)$; Machiavellianism correlated with psychopathy $(r(477)=$ $.49, p<.001)$ and sadism $(r(478)=.41, p<.001)$; and psychopathy significantly correlated with sadism $(r(475)=.86, p<.001)$. The intercorrelations among these variables are consistent with what previous studies have reported (Thibault, 2016; Baloch et al., 2017), which helps mitigate concern that these correlations are due to inconsistencies in the measurement of these variables. 
It does, however, raise some concern for using all of the dark tetrad traits in regression analyses in future research. This concern is addressed in the discussion section of this paper.

\section{Table 1}

\section{Sample Demographics}

\begin{tabular}{lcc}
\hline Sample Characteristic & $n$ & Percent \\
\hline Gender & 205 & 41.8 \\
Male & 259 & 52.7 \\
Female & & \\
Ethnicity & 367 & 74.7 \\
White & 45 & 9.2 \\
Black & 34 & 6.9 \\
Asian & 9 & 1.8 \\
Hispanic/Latino & 6 & 1.2 \\
American Indian/ & & \\
Alaska Native & & .2 \\
Native Hawaiian / & 1 & \\
Pacific Islander & & \\
Other/Multiracial & 2 & .4 \\
Tenure & & \\
< 1 year & 41 & 8.4 \\
1-3 years & 124 & 26.5 \\
3-5 years & 74 & 16.1 \\
5+ years & 201 & 43.8 \\
\hline
\end{tabular}

Note: $n$ represents number of observed cases for each variable. Gender missing 27 cases;

Ethnicity missing 27 cases; Tenure missing 26 cases. 


\section{Table 2}

Means, Standard Deviations, and Correlations of Study Variables

\begin{tabular}{|c|c|c|c|c|c|c|c|c|c|c|c|}
\hline Variable & $n$ & $M$ & $S D$ & 1 & 2 & 3 & 4 & 5 & 6 & 7 & 8 \\
\hline 1. Narcissism & 486 & 17.48 & 5.23 & $(.84)$ & & & & & & & \\
\hline \multicolumn{12}{|l|}{ 2.Machia- } \\
\hline vellianism & 485 & 11.16 & 4.57 & $.17 * *$ & $(.87)$ & & & & & & \\
\hline 3.Psychopathy & 482 & 9.66 & 5.01 & $.35 * *$ & $.49 * *$ & $(.91)$ & & & & & \\
\hline 4. Sadism & 483 & 9.12 & 4.98 & $.37 * *$ & $.41 * *$ & $.86^{* *}$ & $(.93)$ & & & & \\
\hline 5. BLM & 488 & 13.94 & 7.1 & $.16^{* *}$ & $.58 * *$ & $.41 * *$ & $.37 * *$ & $(.94)$ & & & \\
\hline \multicolumn{12}{|l|}{ 6. Job } \\
\hline Satisfaction & 484 & 18.57 & 5.27 & $.17 * *$ & $-.45 * *$ & $-.27 * *$ & $-.24 * *$ & $-.38 * *$ & $(.86)$ & & \\
\hline 7. POP & 469 & 42.09 & 11.75 & 0.08 & $.62 * *$ & $.40 * *$ & $.31 * *$ & $.55^{* *}$ & $-.55^{* *}$ & $(.88)$ & \\
\hline 8. CWB & 486 & 16.62 & 7.03 & $.24 * *$ & $.45^{* *}$ & $.68 * *$ & $.71 * *$ & $.37 * *$ & $-.34 * *$ & $.38 * *$ & $(.90)$ \\
\hline
\end{tabular}

Note. $n$ represents number of cases observed for each variable. Cronbach alphas are reported on the main diagonal. $\mathrm{BLM}=$ bottom-line mentality. $\mathrm{POP}=$ perceptions of organizational politics. CWB = counterproductive work behavior.

$*$ indicates $p<.05 . * *$ indicates $p<.01$.

Table 2 shows that the dark tetrad traits are significantly correlated with BLM, job satisfaction, POP, and CWB. Narcissism correlated with BLM $(r(483)=.16, p=.001)$, job satisfaction $(r(479)=.17, p<.001)$, and CWB $(r(481)=.24, p<.001)$. Narcissism did not significantly correlate with POP $(r(464)=.08, p=.09)$. Machiavellianism significantly correlated with BLM $(r(482)=.58, p<.001)$, job satisfaction $(r(478)=-.48, p<.001)$, POP $(r(463)=.63, p<.001)$, and CWB $(r(480)=.45, p<.001)$. Psychopathy also significantly correlated with BLM $(r(479)=.41, p<.001)$, job satisfaction $(r(475)=-.27, p<.001)$, POP $(r(462)=.40, p<.001)$, and CWB $(r(477)=.68, p<.001)$. Lastly, sadism significantly 
correlated with BLM $(r(480)=.37, p<.001)$, job satisfaction $(r(476)=-.24, p<.001)$, POP $(r(462)=.31, p<.001)$, and CWB $(r(478)=.71, p<.001)$.

Furthermore, Table 2 shows each scale's internal consistency (Cronbach alpha) on the main diagonal. The measures used in this study all displayed good to excellent reliability. The DTW scale displayed a good composite reliability $(\alpha=.89)$, with subscale reliabilities ranging from .84 (narcissism) to .93 (sadism). The revised BLM scale displayed a Cronbach alpha of .94, indicating that including "My supervisor" before each item did not decrease the scale's reliability. The 5-item job satisfaction scale also showed good internal consistency $(\alpha=.86)$ despite being created 1951. The POP scale and the shortened 10-item CWB-C also showed satisfactory levels of internal consistency ( $\alpha=.88 \& .99$, respectively).

Lastly, narcissism, psychopathy, and sadism can all range from 6-30, whereas Machiavellianism can range from 4-20. The means for sadism and psychopathy are considerably lower than the other two dark tetrad traits. This may be due to a lack of these traits in the workplace. Those higher on either sadism or psychopathy may find it difficult to obtain and keep a job since both may be accompanied by criminal records and a carelessness for the well-being of others. Therefore, those with higher levels of sadism or psychopathy would not have met the minimum qualifications for this study.

\section{Hypotheses 1a-d}

The first analysis conducted examined the moderating effect of perceptions of supervisor's BLM on the positive relationship between the dark tetrad and CWB using hierarchical regression analysis. With $\mathrm{CWB}$ as the criterion, the dark tetrad traits and perceptions of supervisor's BLM were entered in step 1. In step 2, the respective interaction terms were entered. 
In Step 1, the model explained 54\% of variance in CWB, $R 2=.54, F(5,466)=110.46, p$ $<.001$. Variance in CWB was significantly predicted by Machiavellianism $(\beta=.14, t(480)=$ $3.40, p=.001)$, psychopathy $(\beta=.18, t(479)=2.82, p=.005)$, and sadism $(\beta=.50, t(477)=$ $8.08, p<.001)$, but not significantly predicted by narcissism $(\beta=-.04, t(480)=-1.14, p=.254)$ $\operatorname{or} \operatorname{BLM}(\beta=.04, t(482)=1.08, p=.281)$.

There was a significant amount of variance explained in step $2, \Delta R_{2}=.01, F(4,462)=$ $3.46, p=.009$. Each interaction term in step 2 , however, did not predict incremental validity in CWB. Hypothesis 1a predicted that at higher levels of BLM, those with narcissistic personalities would engage in more CWB. There was not a significant interaction between BLM and $\operatorname{narcissism}(\beta=.15, t(473)=1.18, p=.24)$, and therefore hypothesis 1a is not supported.

Hypothesis $1 \mathrm{~b}$ predicted that at higher levels of BLM, those with Machiavellian personalities would engage in more CWB. No significant interaction was found between BLM and Machiavellianism $(\beta=.20, t(472)=1.26, p=.21)$, and therefore hypothesis $1 \mathrm{~b}$ is not supported.

Hypothesis 1c predicted that at higher levels of BLM, those higher in psychopathy would engage in more CWB. There was not a significant interaction between BLM and psychopathy ( $\beta$ $=-.44, t(469)=-1.60, p=.24)$, and therefore hypothesis $1 \mathrm{c}$ is not supported.

Lastly, hypothesis $1 \mathrm{~d}$ predicted that there would be a significant interaction between sadism and BLM, such that when BLM is high the frequency of CWB is increased. The interaction between sadism and BLM did provide incremental validity in step $2(\beta=.75, t(470)=2.78, p=.006)$. This hypothesis was supported because there is a significant amount of variance explained by the sadism*BLM interaction term in step 2. Results from this analysis are also available in Table 3. A simple slope analysis shows a nonsignificant simple slope for those who perceived their 
supervisors to have a low BLM $(-1 \mathrm{SD}), b=.17, t(470)=.96, p=.340$. Meanwhile, there were significant simple slopes for those perceiving their supervisor's BLM at the mean (0 SD), $b=$ $.47, t(470)=4.75, p<.000$ and at higher levels $(+1 \mathrm{SD}), b=.78, t(470)=7.17, p<.001(\mathrm{see}$

Figure 4). The results suggest that supervisor's BLM only exacerbates the frequency of engaging in CWB when employees are willing, or prone, to hurting others.

\section{Hypotheses 2a-d}

Hypothesis $2 \mathrm{a}-\mathrm{d}$ predicted that there would be significant negative correlations between the dark tetrad traits and job satisfaction. To test these hypotheses, we examined the bivariate correlations between each trait and job satisfaction. First, hypothesis $2 \mathrm{a}$ predicted a significant negative correlation between job satisfaction and narcissism. Our results show that narcissism was the only dark tetrad trait with a significant positive correlation with job satisfaction $(r(477)=$ $.17, p<.001)$. The observed relationship did not go in the predicted direction, therefore, hypothesis $2 \mathrm{a}$ was not supported. Hypothesis $2 \mathrm{~b}$ predicted that Machiavellianism would have a negative correlation with job satisfaction. We found that indeed, Machiavellianism was negatively correlated with job satisfaction $(r(476)=-.45, p<.001)$. Those higher in Machiavellianism would be expected have lower levels of job satisfaction. Therefore, hypothesis $2 \mathrm{~b}$ is supported. Hypothesis $2 \mathrm{c}$ stated that psychopathy would have a negative correlation with job satisfaction as well. Our results show that there was a significant negative correlation between psychopathy and job satisfaction $(r(473)=-.27, p<.001)$, thus hypothesis $2 \mathrm{c}$ is supported. Those with higher levels of psychopathy are predicted to have lower levels of job satisfaction. Lastly, hypothesis $2 \mathrm{~d}$ predicted that sadism would be negatively correlated with job satisfaction. The results show that sadism did indeed have a negative correlation with job satisfaction $(r(474)=-.24, p<.001$. This lends support for hypothesis $2 \mathrm{~d}$; those higher in sadism 


\section{Table 3}

Hierarchical Regression Analysis Results Using CWB as the Criterion

\begin{tabular}{|c|c|c|c|c|c|c|c|}
\hline Predictor & $b$ & $S E$ & $\beta$ & $s r 2$ & $t$ & $R_{2}$ & $\Delta R_{2}$ \\
\hline \multicolumn{8}{|l|}{ Step 1} \\
\hline (Intercept) & $5.73 * * *$ & 0.88 & & & 6.49 & & \\
\hline Narcissisma & -0.05 & 0.04 & -0.04 & -0.04 & -1.14 & & \\
\hline $\begin{array}{l}\text { Machia- } \\
\text { vellianismb }\end{array}$ & $0.21 * * *$ & 0.06 & $0.14 * * *$ & 0.11 & 3.40 & & \\
\hline Psychopathyc & $0.25 * *$ & 0.09 & $0.18 * *$ & 0.09 & 2.82 & & \\
\hline Sadismd & $0.7 * * *$ & 0.09 & $0.50 * * *$ & 0.25 & 8.08 & & \\
\hline \multirow[t]{2}{*}{ BLMe } & 0.04 & 0.04 & 0.04 & 0.03 & 1.08 & & \\
\hline & & & & & & 0.54 & $.54 * * *$ \\
\hline \multicolumn{8}{|l|}{ Step 2} \\
\hline (Intercept) & $10.89 * * *$ & 1.98 & & & 5.50 & & \\
\hline Narcissism & -0.12 & 0.09 & -0.09 & -0.04 & -1.35 & & \\
\hline $\begin{array}{l}\text { Machia- } \\
\text { vellianism }\end{array}$ & 0.10 & 0.13 & 0.07 & 0.02 & 0.77 & & \\
\hline Psychopathy & $0.58^{*}$ & 0.25 & $0.41 *$ & 0.07 & 2.30 & & \\
\hline Sadism & -0.01 & 0.26 & -0.01 & 0.00 & -0.03 & & \\
\hline BLM & $-0.32 *$ & 0.13 & $-0.32 *$ & -0.08 & -2.44 & & \\
\hline $\mathrm{NxBLM}_{\mathrm{f}}$ & 0.01 & 0.01 & 0.15 & 0.04 & 1.18 & & \\
\hline MxBLMg & 0.01 & 0.01 & 0.20 & 0.04 & 1.26 & & \\
\hline PxBLMh & -0.02 & 0.02 & -0.44 & -0.05 & -1.60 & & \\
\hline \multirow[t]{2}{*}{$\mathrm{SxBLM}_{\mathrm{i}}$} & $0.04 * *$ & 0.02 & $0.75 * *$ & 0.09 & 2.78 & & \\
\hline & & & & & & 0.55 & $.01 * *$ \\
\hline
\end{tabular}

Note. a $n=486$. b $n=485$. с $n=485$. d $n=483$. e BLM = bottom-line mentality, $n=488$.

$\mathrm{fNxBLM}=$ narcissism*BLM interaction term, $n=483 . \mathrm{gMxBLM}=$ Machiavellianism*BLM interaction term, $n=482$. $\mathrm{hPxBLM}=$ psychopathy*BLM interaction term, $n=479$. iSxBLM $=$ sadism*BLM interaction term, $n=480$.

$*$ indicates $p<.05$. ** indicates $p<.01$. *** indicates $p<.001$ 


\section{Figure 4}

Simple Slopes for Sadism predicting CWB at -1, 0 and +1 SD of BLM

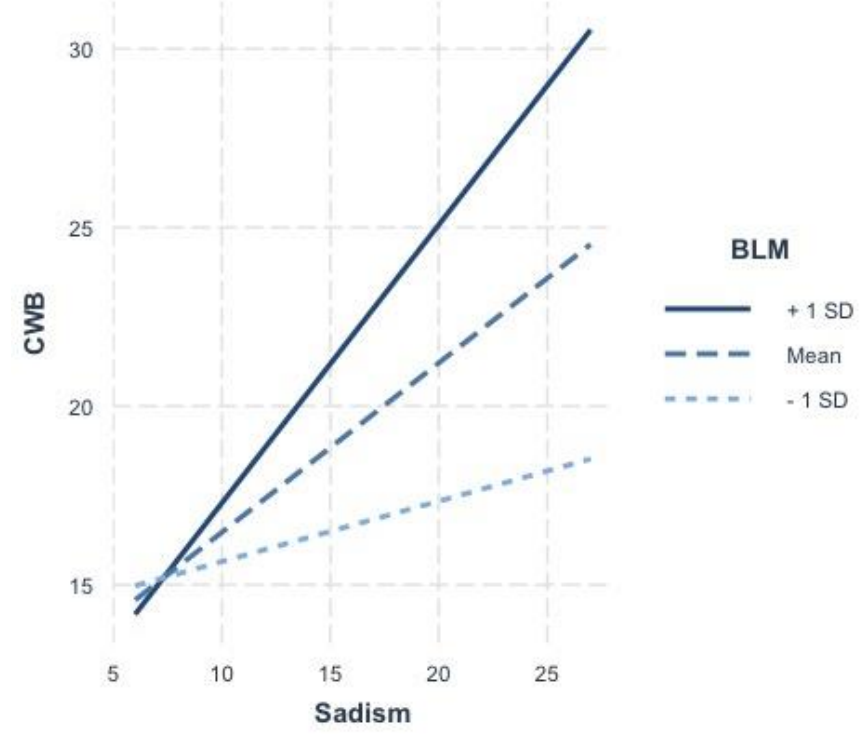

are also likely to have lower levels of job satisfaction. Results from this analysis are also available in Table 2.

\section{Hypotheses 3a-d}

The next set of hypotheses (3a-d) were tested using PROCESS version 3.4 (Hayes, 2017). The significance of all indirect effects was tested using bootstrapping procedures. For each simple mediation analysis, indirect effects were computed for each of 10,000 bootstrapped samples, and the $95 \%$ confidence interval was computed by determining the indirect effects at the 2.5 th and 97.5 th percentiles.

First, we tested hypothesis $3 \mathrm{a}$ which examined the mediating effect of job satisfaction on the relationship between narcissism and CWB. The unstandardized regression coefficient between narcissism and job satisfaction was statistically significant, as was the unstandardized regression coefficient between job satisfaction and CWB. The indirect effect was $(.17)(-.52)=-$ .09. The bootstrapped $95 \%$ confidence interval for the indirect effect ranged from -.14, -.04. The 
exclusion of zero from the confidence interval indicates that the indirect effect is statistically significant and hypothesis 3a was supported.

The same simple mediation method was used to test the mediating role of job satisfaction between Machiavellianism and CWB. The results showed that the relationship between Machiavellianism and CWB was partially mediated by job satisfaction. The unstandardized regression coefficient between Machiavellianism and job satisfaction was statistically significant, as was the unstandardized regression coefficient between job satisfaction and CWB. The indirect effect was $(-.52)(-.23)=.12$. The bootstrapped $95 \%$ confidence interval for the indirect effect ranged from $.07, .18$. Thus, the indirect effect was statistically significant and hypothesis $3 \mathrm{~b}$ is supported.

The relationship between psychopathy and CWB was partially mediated by job satisfaction. Simple mediation showed the unstandardized regression coefficient between psychopathy and job satisfaction was statistically significant, as was the unstandardized regression coefficient between job satisfaction and CWB. The indirect effect was $(-.28)(-.23)=$ .06. The bootstrapped $95 \%$ confidence interval for the indirect effect ranged from $.04, .10$. These results also indicate support for hypothesis 3c.

Finally, the relationship between sadism and CWB was also partially mediated by job satisfaction. The unstandardized regression coefficient between sadism and job satisfaction was statistically significant, as was the unstandardized regression coefficient between job satisfaction and CWB. The indirect effect was $(-.25)(-.24)=.06$. The bootstrapped $95 \%$ confidence interval for the indirect effect ranged from $.04, .09$. Thus, the indirect effect was statistically significant and hypothesis $3 \mathrm{~d}$ is supported. 


\section{Hypothesis 4}

Hypothesis 4 predicted that the relationship between sadism and CWB would be mediated by POP. A simple mediation analysis revealed that POP does partially mediate this relationship. The unstandardized regression coefficient between sadism and POP was statistically significant, as was the unstandardized regression coefficient between POP and CWB. The indirect effect was $(.74)(.10)=.07$. We tested the significance of this indirect effect using bootstrapping procedures. Indirect effects were computed for each of 10,000 bootstrapped samples, and the $95 \%$ confidence interval was computed by determining the indirect effects at the 2.5 th and 97.5 th percentiles. The bootstrapped $95 \%$ confidence interval for the indirect effect ranged from $.05, .10$. Thus, the indirect effect was statistically significant and hypothesis 4 is supported.

\section{Post-Hoc Analysis}

One goal of this study was to gather further evidence of validity for the DTW scale. In search for criterion-related validity, a multiple regression analysis with pairwise deletion was conducted with CWB as the criterion and the dark tetrad traits as the predictors. The proposed regression model explained a significant amount of variance in CWB, $R_{2}=.54, F(4,470)=$ $138.62, p<.001$. Narcissism was the first predictor in the model and did not explain a significant amount of variance in CWB $(\beta=-.04, t(480)=-1.13, p=.260)$. Scores in CWB were significantly predicted by Machiavellianism $(\beta=.16, t(479)=4.48, p<.001)$, psychopathy $(\beta=$ $.18, t(476)=2.90, p=.004)$, and sadism $(\beta=.50, t(477)=8.16, p<.001)$. Collinearity of the independent variables was also examined in this analysis. The general rule for detecting multicollinearity is that variables with tolerance levels less than .10 indicate serious multicollinearity (Tabachnick et al., 2007, p.144). Only psychopathy and sadism showed 
tolerance values that suggest multicollinearity may be an issue. The tolerance values for psychopathy and sadism were .24 and .26 , respectively. Although these values do not meet the minimum tolerance cutoff value, the tolerance values indicate that a fair amount of multicollinearity is present in this model. Due to the presence of moderate to high multicollinearity, these results need to be interpreted with caution. Multicollinearity does not change the power or validity of the test as a whole, however, it does have an effect on the power of tests for the individual predictors (Darlington \& Hayes, 2016, p.109-112). With respect to this regression model, this means that the standard errors of the individual partial regression slopes have been inflated and thus the individual variable predictions are not as accurate; the model as a whole is still valid.

Another hierarchical regression analysis was conducted to examine the incremental validity of sadism over the other dark tetrad traits. Using CWB as the criterion, narcissism, Machiavellianism, and psychopathy were entered in step one; sadism was entered in step two. In step one, the model explained $48 \%$ of variance in $\mathrm{CWB}, R_{2}=.48, F(3,471)=142.76, p<.001$. In step two, sadism predicted an additional $6.5 \%$ of variance in $\mathrm{CWB}, \Delta R_{2}=.065, F(1,470)=$ $66.57, p<.001$. These results highlight the importance of including sadism when conducting research on dark personality in the workplace. 


\section{CHAPTER V: DISCUSSION OF RESULTS}

\section{Discussion}

\section{Summary of Results}

This study was mainly designed to test specific conditions in which the dark tetrad traits can manifest as CWB. Our first set of hypotheses (1a-d) predicted that all four traits would have a significant interaction with perceptions of supervisor's BLM. We found that only the sadism*BLM interaction term provided incremental validity in the hierarchical regression model. One possible explanation for this finding is that after accounting for variance explained by sadism (i.e., a tendency to inflict harm on others), the other dark tetrad traits do not interact with BLM in a way that exacerbates deviant workplace behavior. These results suggest that when perceived supervisor's BLM is high, only those with sadistic tendencies take advantage of the situation and engage in more CWB. In an organization, this phenomenon could manifest as a cutthroat or zero-sum culture.

The predictions made in hypotheses $2 \mathrm{~b}$-d were all supported; Machiavellianism, psychopathy, and sadism all had significant negative correlations with job satisfaction. This can be interpreted as at higher levels of these traits, one would be expected to have lower levels of job satisfaction. We proposed two explanations for these results. First, there could be a dispositional aspect that covaries with the dark tetrad leading to lower levels of job satisfaction. An alternative explanation is that those higher in these traits tend to behave in a manipulative, abusive, and self-interested manner. Engaging in this type of behavior may provoke ostracism or other forms of retaliation from others in the organization, which can lead to lower levels of job satisfaction (Ferris et al., 2008; Lim et al., 2008). We did not find support for hypothesis 2a; narcissism had a significant positive correlation with job satisfaction. Since job satisfaction was 
measured using a subjective self-rating, it is plausible that those higher in narcissism are compelled to believe they are satisfied at work in order to uphold their grandiose sense of themselves. Whether their level of satisfaction is real, or merely a product of self-deception, is beyond the scope of this study.

We also found support for hypotheses 3a-d which predicted that job satisfaction would mediate the relationships between the dark tetrad traits and CWB. Our results show that job satisfaction only partially mediated these relationships; there was still a significant direct effect between $\mathrm{X}$ and $\mathrm{Y}$ (c') after accounting for the variance explained through job satisfaction. Interestingly, the significant c' paths indicate that some individuals engage in CWB regardless of their level of job satisfaction. Interestingly, the relationship between narcissism and job satisfaction is positive unlike the relationships job satisfaction has with the other dark tetrad traits, and yet we found that job satisfaction still mediated this relationship. One explanation for this finding is that those higher in narcissism may be engaging in self-deception to make themselves think they are satisfied at work in order to validate their inflated sense of themselves. Since the path $\mathrm{b}$ coefficient is negative, we can tell that those with narcissism are still engaging in CWB despite reporting higher levels of job satisfaction. The special case with narcissism along with the strong c' paths show the importance of using personality measures for selection purposes since these traits appear to lead people to engage in CWB regardless of their selfreported levels of job satisfaction.

The last hypothesis we tested examined the mediating role of POP between sadism and CWB. We found that POP partially mediated the relationship. After accounting for the indirect effect, there was still a significant c' path. This finding is similar to those reported in Baloch et al. (2017), in which POP partially mediated the relationships between the other dark tetrad traits 
and CWB. It appears that either there are other mediators of this relationship, or the significant direct effect is a product of the dispositional nature of sadism.

The post-hoc multiple regression analysis showed that the DTW scale predicted $54 \%$ of variance in CWB. Similar results were found in Thibault (2016), where she reported the DTW scale explained between $42-50 \%$ of CWB. Interestingly, sadism emerged as the strongest predictor of CWB in both studies. Due to the influence of multicollinearity, the safest conclusion that should be drawn is that the dark tetrad (as a whole) significantly predicts CWB. Overall, the amount of variance explained by the dark tetrad was much greater than the amount explained by the Big Five (5-10\%; Wu \& LeBreton, 2011) or the dark triad (28\%; O'Boyle et al., 2012). The issue of multicollinearity is not specific to the use of the DTW scale. Thibault (2016) reported that psychopathy and sadism are also highly correlated when measured using separate scales of these two constructs. The Short Dark Triad (SD3; Paulhus \& Jones, 2011) psychopathy scale has a strong .71 raw correlation with the DTW sadism scale and a raw correlation of .79 with the VAST (Paulhus \& Jones, 2015) direct sadism scale. The lack of literature on the dark tetrad compared to the dark triad also makes it difficult to fully assess the impact of the multicollinearity between psychopathy and sadism. Another study which examined the dark tetrad traits found a much lower correlation between psychopathy and sadism. Kircaburun et al. (2018) reported a correlation of .50 between psychopathy and sadism. One explanation for obtaining lower amount of collinearity is that the study used short versions of dark tetrad measures which displayed questionable levels of reliability for psychopathy $(\alpha=.66)$ and acceptable reliability for sadism $(\alpha=.74)$. The unreliability of these measures would have introduced variability into the scores and thus lowed the collinearity among their independent variables. Another explanation could be that by using a contextualized measure (i.e. the DTW 
scale), the situational constraints put in place may have reduced variability in behavior and led to higher collinearity.

\section{Limitations and Future Research}

One of the limitations for this study was that we used perceptions of supervisor's BLM as a substitute for self-reported BLM. Although psychologists have long recognized the importance of perceptions in predicting behavior (Lewin, 1936), its plausible that some supervisors engage in impression management to dilute the appearance of their own BLM in front of their employees. Future research could benefit from collecting both self-reported and other-reported levels of supervisor's BLM.

Another limitation is that this study did not control for social desirability. It is possible that social desirability may account for some of the explained variance between the variables in this study. However, since the survey was taken anonymously online there is also reason to believe that any effects due to social desirability were mitigated. We suggest that future research include a measure for social desirability to increase the accuracy of the individual variable predictions.

The cross-sectional nature of the data collected for this study limits the ability to draw causal inferences from the results. Temporal precedence needs to be established in order to draw any causal inferences from mediation models (MacKinnon et al., 2007). Future research should conduct a longitudinal study in which one could prove that changes in job satisfaction and POP lead to changes in CWB, and not the other way around. Since mediation relies on correlational methods (i.e., regression), it will also be imperative to identify any other covariates that could explain the observed effects in order to show causation (e.g., negative affect). 
We also offer two areas that future research may want to address in addition to these limitations. First, these results may vary by occupation or industry. For example, someone in the retail industry is going to be afforded more opportunity to steal merchandise than is an insurance salesman. Those with dark personalities may even be attracted to these types of jobs. Second, the POP measure consists of three subscales. It is possible that the different dark tetrad traits may be more likely to engage in certain types of political behavior at work. An example would be someone higher in Machiavellianism that is always looking for ways to advance their own interests. They would most likely engage in go along to get ahead behavior (e.g., not speak against wrongful termination) since going along would make them part of the in-group and not jeopardize their job by speaking out against it.

\section{Research Implications}

The results from this study carry implications for future research examining relationships between personality and important work outcomes. First, sadism emerged as the strongest predictor of CWB in both hierarchical regression analyses; sadism also had the second largest negative correlation with job satisfaction. These findings offer some justification for including sadism when examining the relationships between dark personality and organizationally relevant criterion. As previously noted, since the proposal of the dark tetrad at least 588 studies have excluded sadism and only used the dark triad. Due to publication bias, it is likely that even more studies have failed to find significant results and thus were not published. As long as authors can provide theoretical justification for including sadism, any such studies may want to re-evaluate their hypotheses or models to include sadism. As the amount of literature on the dark tetrad grows, there will also be a future opportunity to evaluate the meta-analytic effect size of sadism and the dark tetrad. 
Next, this study benefitted from being able to collect responses anonymously in a low risk setting. Unfortunately, implementing the DTW scale for pre-employment purposes may not provide such robust results. The items in the DTW scale might be too easy for applicants to fake their responses to. For example, one item is "I don't care if my work behavior hurts others." This opens a new opportunity for future research to use this scale in an organizational setting to see if this scale will need to be revised in order to be effective for applicant selection.

Multicollinearity among predictors is more of a problem for researchers than practitioners because researchers often want to know effects from the individual predictors and not just the model prediction. One possible way to mitigate this issue in future research is to move past measures of the dark tetrad and begin looking at the dark factor of personality (Moshagen et al., 2018). Through factor analysis, a latent dark core construct was identified as the dark factor in which all other dark personality traits manifest from. This measure would allow researchers to conduct regression analyses without the issue of multicollinearity and still be able to examine individual effects at the facet-level.

\section{Practical Implications}

A meta-analysis conducted by O'Boyle et al. (2012) discovered that in the few instances of which measures of the dark tetrad were used to screen applicants, they relied almost entirely on scales measuring clinical psychopathy. As noted in Melson-Silimon et al. (2019), the use of clinical measures of the dark tetrad for selection purposes could be illegal under the ADA (1990); organizations are not allowed to use medical test (including clinical measures) for selection purposes. Fortunately, the DTW scale provides a highly reliable and valid measure that is well-suited for selection purposes because it does not rely on clinical measures of the dark 
tetrad traits. Therefore, the DTW scale could not be considered a medical test and would not violate the ADA (1990).

The DTW scale has not been studied under real organizational contexts which gives cause for concern to applicants or employees being able to fake on this measure. For example, deception and manipulation are two characteristics of psychopathy and Machiavellianism that are likely to manifest in real selection situations when the stakes are higher. For this reason, organizations may find it beneficial to look for real behaviors that would show someone would backstab their coworker (e.g. I would sell my products in another coworker's territory) instead of asking it explicitly. We did not include a measure of social desirability due to the low risk context of collecting the data for this study. It is recommended that organizations include a measure of social desirability when using this scale in selection contexts to try and offset some of the faking occurring in real organizational contexts.

Organizations already using other personality measures (e.g., the Big Five) for selection purposes could further benefit from including this measure of the dark tetrad. Our results, in addition to those in Thibault (2016) and O'Boyle et al. (2012), show that the dark tetrad predicts more variance in CWB than measures of the Big Five personality traits. The return on investment for implementing this screening tool could be significant, considering U.S. organizations lose \$50-\$400 billion dollars a year from CWB (Wells, 1999; Coffin, 2003).

In addition to benefitting from a scale that predicts CWB better than the Big Five, future research may show that the dark tetrad can predict other important outcomes such as job performance or leadership potential. As the literature on sadism expands, the DTW scale may prove to be more versatile than expected. 


\section{Conclusion}

This study has found that the DTW scale is both a reliable and valid measure of the subclinical levels of the dark tetrad. Our findings bolster those from previous studies showing that the dark tetrad, specifically in regard to sadism, is highly effective in predicting CWB among other organizationally relevant criteria. Furthermore, we added to the dearth of literature on sadism in the workplace by identifying a moderator and partial mediators of its positive relationship with CWB. Lastly, various studies reported differences in the magnitude and direction of the bivariate relationships of the dark tetrad traits with job satisfaction. We offer another study which can be utilized to help elucidate the true association between these constructs and why these differences emerged within the literature. 


\section{REFERENCES}

Americans With Disabilities Act of 1990, Pub. L. No. 101-336, 104 Stat. 328 (1990).

American Psychiatric Association. (2013). Diagnostic and statistical manual of mental disorders (5th ed.). https://doi.org/10.1176/appi.books.9780890425596

Baloch, M. A., Meng, F., Xu, Z., Cepeda-Carrion, I., \& Bari, M. W. (2017). Dark Triad, Perceptions of Organizational Politics and Counterproductive Work Behaviors: The Moderating Effect of Political Skills. Frontiers in Psychology, 8, 1972. https://doi.org/10.3389/fpsyg.2017.01972

Bamfield, J. (2010). The Global Retail Theft Barometer 2010: Monitoring the Costs of Shrinkage and Crime in the Global Retail Industry. Centre for Retail Research.

Bolton, L. R., Becker, L. K., \& Barber, L. K. (2010). Big Five trait predictors of differential counterproductive work behavior dimensions. Personality and Individual Differences, 49(5), 537-541. https://doi.org/10.1016/j.paid.2010.03.047

Bradley-Geist, J. C., \& Landis, R. S. (2012). Homogeneity of personality in occupations and organizations: A comparison of alternative statistical tests. Journal of Business and Psychology, 27(2), 149-159. https://doi.org/10.1007/s10869-011-9233-6 https://doi.org/10.1007/s10869-011-9233-6

Brayfield, A. H., \& Rothe, H. F. (1951). An index of job satisfaction. Journal of Applied Psychology, 35(5), 307. https://doi.org/10.1037/h0055617

Brower, C.K., Bowling, N. A. (2017, April). The quick and the careless: Using page time to measure careless responding. Presented at Wright State University's research conference, Celebration of Research, Scholarship, and Creative Activities, Dayton, $\mathrm{OH}$. 
Buckels, E. E., Jones, D. N., \& Paulhus, D. L. (2013). Behavioral confirmation of everyday sadism. Psychological Science, 24(11), 2201-2209. https://doi.org/10.1177/0956797613490749

Chabrol, H., Van Leeuwen, N., Rodgers, R., \& Séjourné, N. (2009). Contributions of psychopathic, narcissistic, Machiavellian, and sadistic personality traits to juvenile delinquency. Personality and Individual Differences, 47(7), 734-739. https://doi.org/10.1016/j.paid.2009.06.020

Chang, C. H., Rosen, C. C., \& Levy, P. E. (2009). The relationship between perceptions of organizational politics and employee attitudes, strain, and behavior: A meta-analytic examination. Academy of Management journal, 52(4), 779-801. https://doi.org/10.5465/amj.2009.43670894

Christie, R. C., \& Geis, F. L. (1970). Studies in Machiavellianism. New York: Academic press. Clifford, S., \& Jerit, J. (2015). Do attempts to improve respondent attention increase social desirability bias?. Public Opinion Quarterly, 79(3), 790-802. doi:10.1093/poq/nfv027

Cohen, A. (2016). Are they among us? A conceptual framework of the relationship between the dark triad personality and counterproductive work behaviors (CWBs). Human Resource Management Review, 26(1), 69-85. https://doi.org/10.1016/j.hrmr.2015.07.003

Connolly, J. J., \& Viswesvaran, C. (2000). The role of affectivity in job satisfaction: A metaanalysis. Personality and Individual Differences, 29, 265-281. https://doi.org/10.1016/S0191-8869(99)00192-0

Costa Jr, P. T., \& McCrae, R. R. (1995). Domains and facets: Hierarchical personality assessment using the Revised NEO Personality Inventory. Journal of Personality Assessment, 64(1), 21-50. https://doi.org/10.1207/s15327752jpa6401_2 
Darlington, R. B., \& Hayes, A. F. (2016). Regression analysis and linear models: Concepts, applications, and implementation. p109-112. Guilford Publications.

De Cooman, R., De Gieter, S., Pepermans, R., Hermans, S., Du Bois, C., Caers, R., \& Jegers, M. (2009). Person-organization fit: Testing socialization and attraction-selection-attrition hypotheses. Journal of Vocational Behavior, 74(1), 102-107. https://doi.org/10.1016/j.jvb.2008.10.010

Crede, M., Chernyshenko, O. S., Stark, S., Dalal, R. S., \& Bashshur, M. (2007). Job satisfaction as mediator: An assessment of job satisfaction's position within the nomological network. Journal of Occupational and Organizational Psychology, 80(3), 515-538. https://doi.org/10.1348/096317906X136180

Coffin, B. (2003). Breaking the silence on white collar crime. Risk Management, 50(9), 8-9.

Cropanzano, R., \& Mitchell, M. S. (2005). Social exchange theory: An interdisciplinary review. Journal of Management, 31(6), 874-900. https://doi.org/10.1177/0149206305279602

Duffy, M. K., Ganster, D. C., \& Pagon, M. (2002). Social undermining in the workplace. Academy of Management Journal, 45(2), 331-351. https://doi.org/10.2307/3069350

Eisenberger, R., Huntington, R., Hutchison, S., \& Sowa, D. (1986). Perceived organizational support. Journal of Applied psychology, 71(3), 500. https://doi.org/10.1037/00219010.71 .3 .500

Ferris, D. L., Brown, D. J., Berry, J. W., \& Lian, H. (2008). The development and validation of the Workplace Ostracism Scale. Journal of Applied Psychology, 93(6), 1348-1366. https://doi-org.libproxy.lib.ilstu.edu/10.1037/a0012743

Ferns, G. R., Adams, G. L., Kolodinsky, R. W., Hochwarter, W. A., \& Ammeter, A. P. (2002). Perceptions of politics: Theory and research directions. In F. Dansereau \& F. Y. 
Yammarino (Eds.), Research in multi-level issues (Vol. 1, pp. 179-254), Oxford, UK: Elsevier Science/JAI Press.

Ferris, G. R., Harrell-Cook, G., \& Dulebohn, J. (2000). Organizational politics: The nature of the relationship between politics perceptions and political behavior. Research in the Sociology of Organizations, 17, 89-130. https://doi.org/10.1016/S0733-558X(00)17004-1

Fritz, M. S., \& MacKinnon, D. P. (2007). Required sample size to detect the mediated effect. Psychological Science, 18(3), 233-239. https://doi.org/10.1111/j.14679280.2007.01882.x

Greenbaum, R. L., Mawritz, M. B., \& Eissa, G. (2012). Bottom-line mentality as an antecedent of social undermining and the moderating roles of core self-evaluations and conscientiousness. Journal of Applied Psychology, 97(2), 343-359. https://doi:10.1037/a0025217

Gouldner, A. W. (1960). The norm of reciprocity: A preliminary statement. American Sociological Review, 161-178. https:// doi:10.2307/2092623

Hastings, S. E., \& O'Neill, T. A. (2009). Predicting workplace deviance using broad versus narrow personality variables. Personality and Individual Differences, 47(4), 289-293. https://doi.org/10.1016/j.paid.2009.03.015

Hayes, A. F. (2017). Introduction to Mediation, Moderation, and Conditional Process Analysis, Second Edition: A Regression-Based Approach. United States: Guilford Publications.

Henle, C. A., Reeve, C. L., \& Pitts, V. E. (2010). Stealing time at work: Attitudes, social pressure, and perceived control as predictors of time theft. Journal of Business Ethics, 94(1), 53-67. https://doi.org/10.1007/s10551-009-0249-z

Huang, J. L., Curran, P. G., Keeney, J., Poposki,E. M., \& DeShon, R. P. (2012).50 
Detecting and deterring insufficient effort responding to surveys. Journal of Business and Psychology,27(1), 99-114. doi:10.1007/s10869-011-9231-8

Jones, D. N., \& Paulhus, D. L. (2017). Duplicity among the dark triad: Three faces of deceit. Journal of Personality and Social Psychology, 113(2), 329.

Judge, T. A., \& Ilies, R. (2004). Affect and job satisfaction: a study of their relationship at work and at home. Journal of Applied Psychology, 89(4), 661. https://doi.org/10.1037/00219010.89.4.661

Kacmar, K. M., \& Carlson, D. S. (1997). Further validation of the perceptions of politics scale (POP): A multiple sample investigation. Journal of Management, 23(5), 627-658. https://doi.org/10.1177/014920639702300502

Kircaburun, K., Jonason, P. K., \& Griffiths, M. D. (2018). The Dark Tetrad traits and problematic social media use: The mediating role of cyberbullying and cyberstalking. Personality and Individual Differences, 135, 264-269. DOI: 10.1016/j.paid.2018.07.034

LeBreton, J. M., Binning, J. F., \& Adorno, A. J. (2006). Subclinical Psychopaths. In J. C. Thomas, D. L. Segal, \& M. Hersen (Eds.), Comprehensive Handbook of Personality and Psychopathology, Vol. 1. Personality and Everyday Functioning (p. 388-411). John Wiley \& Sons Inc.

LeBreton, J. M., Shiverdecker, L. K., \& Grimaldi, E. M. (2018). The dark triad and workplace behavior. Annual Review of Organizational Psychology and Organizational Behavior, 5, 387-414. https://doi.org/10.1146/annurev-orgpsych-032117-104451

Lewin, K. (1936). Principles of topological psychology. New York: McGraw-Hill. 
Lim, S., Cortina, L. M., \& Magley, V. J. (2008). Personal and workgroup incivility: Impact on work and health outcomes. Journal of Applied Psychology, 93(1), 95-107. https://doiorg.libproxy.lib.ilstu.edu/10.1037/0021-9010.93.1.95

MacKinnon, D. P., Fairchild, A. J., \& Fritz, M. S. (2007). Mediation analysis. Annu. Rev. Psychol., 58, 593-614.

Mathieu, C. (2013). Personality and job satisfaction: The role of narcissism. Personality and Individual Differences, 55(6), 650-654. https://doi.org/10.1016/j.paid.2013.05.012

McClelland, G. H., Irwin, J. R., Disatnik, D., \& Sivan, L. (2017). Multicollinearity is a red herring in the search for moderator variables: A guide to interpreting moderated multiple regression models and a critique of Iacobucci, Schneider, Popovich, and Bakamitsos (2016). Behavior research methods, 49(1), 394-402.

Melson-Silimon, A., Harris, A. M., Shoenfelt, E. L., Miller, J. D., \& Carter, N. T. (2019). Personality testing and the Americans with Disabilities Act: Cause for concern as normal and abnormal personality models are integrated. Industrial and Organizational Psychology, 12(2), 119-132. https://doi.org/10.1017/iop.2018.156

Miller, B. K., Rutherford, M. A., \& Kolodinsky, R. W. (2008). Perceptions of organizational politics: A meta-analysis of outcomes. Journal of Business and Psychology, 22(3), 209222. https://doi.org/10.1007/s10869-008-9061-5

Miller, J. D., Hyatt, C. S., Maples-Keller, J. L., Carter, N. T., \& Lynam, D. R. (2017). Psychopathy and Machiavellianism: A distinction without a difference?. Journal of Personality, 85(4), 439-453. https://doi.org/10.1111/jopy.12251

Min, H., Pavisic, I., Howald, N., Highhouse, S., \& Zickar, M. J. (2019). A systematic comparison of three sadism measures and their ability to explain workplace mistreatment 
over and above the dark triad. Journal of Research in Personality, 82. https://doi.org/10.1016/j.jrp.2019.103862

Mount, M., Ilies, R., and Johnson, E. (2006). Relationship of personality traits and counterproductive work behaviors: The mediating effects of job satisfaction. Personnel Psychology. 59(3), 591-622. https://doi.org/10.1111/j.1744-6570.2006.00048.x

Murphy, K. R. 1993. Honesty in the workplace. Belmont, CA: Brooks/Cole.

Nye, L. G., \& Witt, L. A. (1993). Dimensionality and construct validity of the Perceptions of Organizational Politics Scale (POPS). Educational and Psychological Measurement, 53(3), 821-829. https://doi.org/10.1177/0013164493053003026

O’Boyle, E. H., JR, Forsyth, D. R., Banks, G. C., \& McDaniel, M. A. (2012). A meta-analysis of the dark triad and work behavior: a social exchange perspective. Journal of Applied Psychology, 97, 557-579. https://doi.org/10.1037/a0025679

Parker, C. P., Baltes, B. B., Young, S. A., Huff, J. W., Altmann, R. A., Lacost, H. A., \& Roberts, J. E. (2003). Relationships between psychological climate perceptions and work outcomes: a meta-analytic review. Journal of Organizational Behavior: The International Journal of Industrial, Occupational and Organizational Psychology and Behavior, 24(4), 389-416. https://doi.org/10.1002/job.198

Paulhus, D. L., \& Williams, K. M. (2002). The dark triad of personality: Narcissism, Machiavellianism, and psychopathy. Journal of Research in Personality, 36(6), 556-563. https://doi.org/10.1016/S0092-6566(02)00505-6

Penney, L. M., \& Spector, P. E. (2005). Job stress, incivility, and counterproductive work behavior (CWB): The moderating role of negative affectivity. Journal of Organizational 
Behavior: The International Journal of Industrial, Occupational and Organizational Psychology and Behavior, 26(7), 777-796. https://doi.org/10.1002/job.336

Raskin, R. N., \& Hall, C. S. (1979). Narcissistic Personality Inventory. Psychological Reports, 45, 590. https://doi.org/10.2466/pr0.1979.45.2.590

Reichin, S. L., Grimaldi, E. M., \& LeBreton, J. M. (2019). Critically evaluating the use of dark trait measurement in selection. Industrial and Organizational Psychology, 12(2), 163166. https://doi.org/10.1017/iop.2019.32

Rosen, C. C., \& Levy, P. E. (2013). Stresses, swaps, and skill: An investigation of the psychological dynamics that relate work politics to employee performance. Human Performance, 26(1), 44-65. https://doi.org/10.1080/08959285.2012.736901

Satterwhite, R. C., Fleenor, J. W., Braddy, P. W., Feldman, J., \& Hoopes, L. (2009). A case for homogeneity of personality at the occupational level. International Journal of Selection and Assessment, 17(2), 154-164. https://doi.org/10.1111/j.1468-2389.2009.00459.x

Schneider, B. (1987). The people make the place. Personnel Psychology. 40, 437-454. http://dx.doi.org/10.1111/j.1744-6570.1987.tb00609.x

Settoon, R. P., Bennett, N., \& Liden, R. C. (1996). Social exchange in organizations: Perceived organizational support, leader-member exchange, and employee reciprocity. Journal of Applied Psychology, 81(3), 219. https://doi.org/10.1037/0021-9010.81.3.219

Spector PE, Bauer JA, Fox S. (2010). Measurement artifacts in the assessment of counterproductive work behavior and organizational citizenship behavior: Do we know what we think we know? Journal of Applied Psychology. 95(4):781-790. https://doi.org/10.1037/a0019477 
Spector, P. E., \& Fox, S. (2002). An emotion-centered model of voluntary work behavior: Some parallels between counterproductive work behavior and organizational citizenship behavior. Human Resource Management Review, 12(2), 269-292. https://doi.org/10.1016/S1053-4822(02)00049-9

Spector, P. E., \& Fox, S. (2005). The Stressor-Emotion Model of Counterproductive Work Behavior. In S. Fox \& P. E. Spector (Eds.), Counterproductive work behavior: Investigations of actors and targets. (pp. 151-174). Washington, DC: American Psychological Association. https://doi.org/10.1037/10893-007

Spector, P. E., Fox, S., Penney, L. M., Bruursema, K., Goh, A., \& Kessler, S. (2004). Development of the Counterproductive Work Behavior Checklist (CWB-C). Unpublished paper, University of South Florida, Tampa.

Spector, P. E., Fox, S., Penney, L. M., Bruursema, K., Goh, A., \& Kessler, S. (2006). The dimensionality of counterproductivity: Are all counterproductive behaviors created equal?. Journal of Vocational Behavior, 68(3), 446-460. https://doi.org/10.1016/j.jvb.2005.10.005

Stritch, J. M., Pedersen, M. J., \& Taggart, G. (2017). The opportunities and limitations of using Mechanical Turk (Mturk) in public administration and management scholarship. International Public Management Journal, 20(3), 489-511. https://doi.org/10.1080/10967494.2016.1276493

Tabachnick, B. G., Fidell, L. S., \& Ullman, J. B. (2007). Using multivariate statistics (Vol. 5, pp.144). Boston, MA: Pearson.

Thibault, T., Kelloway, E. K. (2016). Interactive Components of the Dark Tetrad at Work. Paper accepted for presentation at the British Academy of Management, Newcastle, UK. 
Thibault, T. (2016). The Dark Tetrad at Work. [Master's thesis, Saint Mary's Univeristy]. http://library2.smu.ca/handle/01/26622\#.XjI6RRNTnOQ

Thibaut, J. W. (1959). Kelley. HH (1959). The social psychology of groups. New York.

Vannette, David L. (2016). Testing the Effects of Different Types of Attention Interventions on Data Quality in Web Surveys. Experimental Evidence From a 14 Country Study. Paper presented at the 71st Annual Conference of the American Association for Public Opinion Research in Austin, TX.

Vize, C. E., Lynam, D. R., Collison, K. L., \& Miller, J. D. (2018). Differences among dark triad components: A meta-analytic investigation. Personality Disorders: Theory, Research, and Treatment, 9(2), 101. https://doi.org/10.1037/per0000222

Wells, J.T. (1999). A fistful of dollars. Security Management, 43(8), 70-75.

Wu, J., \& Lebreton, J. M. (2011). Reconsidering the dispositional basis of counterproductive work behavior: The role of aberrant personality. Personnel Psychology, 64(3), 593-626. https://doi.org/10.1111/j.1744-6570.2011.01220.x 


\section{APPENDIX A: DARK TETRAD AT WORK SCALE \\ Thibault (2016)}

Participants record their response on a 5-point scale from 1 (strongly disagree) to 5 (strongly agree).

Narcissism

1. My position at work is prestigious.

2. I am much more valuable than my coworkers.

3. I demand respect at work.

4. People always pay attention to me at work.

5. Others admire me at work.

6. I like being the center of attention at work

Machiavellianism

7. I do not trust others at work.

8. At work, you always have to look out for number one.

9. At work, people backstab each other to get ahead.

10. At work, people are only motivated by personal gain.

Psychopathy

11. I don't care if my work behavior hurts others.

12. I have been told I act rashly at work.

13. When I'm at work, I don't tend to think about the consequences of my actions. 
14. I like to mooch off my coworkers.

15. I'm rather insensitive at work.

16. I don't care if I accidently hurt someone at work.

Sadism

17. I love to watch my boss yelling at my coworkers.

18. I can dominate others at work using fear.

19. It's funny to watch people make mistakes at work.

20. I never get tired of mocking my coworkers.

21. I would laugh if I saw someone get fired.

22. I have daydreams about hurting people I work with. 


\section{APPENDIX B: COUNTERPRODUCTIVE WORK BEHAVIOR - CHECKLIST \\ Spector et al. (2006)}

Participants record their response on a 5-point scale from 1 (never) to 5 (daily).

1. Purposely wasted your employer's materials/supplies

2. Complained about insignificant things at work

3. Told people outside the job what a lousy place you work for

4. Came to work late without permission

5. Stayed home from work and said you were sick when you weren't

6. Insulted someone about their job performance

7. Made fun of someone's personal life

8. Ignored someone at work

9. Started an argument with someone at work

10. Insulted or made fun of someone at work 


\section{APPENDIX C: BOTTOM-LINE MENTALITY SCALE}

Greenbaum et al. (2012)

Participants record their response on a 7-point scale ranging from 1 (strongly disagree) to 7 (strongly agree).

Other-Report of Supervisor Scale

1. Is solely concerned with meeting the bottom line.

2. Only cares about the business.

3. Treats the bottom line as more important than anything else.

4. Cares more about profits than well-being. 


\section{APPENDIX D: JOB SATISFACTION SCALE \\ Brayfield and Rothe (1951)}

Participants record their responses on a 5-point scale ranging from 1 (strongly disagree) to 5 (strongly agree).

1. I feel fairly well satisfied with my present job

2. Most days I am enthusiastic about my work

3. Each day of work seems like it will never end (R)

4. I find real enjoyment in my work

5. I consider my job rather unpleasant (R) 


\section{APPENDIX E: PERCEPTIONS OF ORGANIZATIONAL POLITICS SCALE}

\section{Kacmar and Carlson (1997)}

Participants record their response on a 5-point scale ranging from 1 (strongly disagree) to 5 (strongly agree).

1. People in this organization attempt to build themselves up by tearing others down

2. There has always been an influential group in this organization that no one ever crosses

3. Employees are encouraged to speak out frankly even when they are critical of well established ideas $(\mathrm{R})$

4. There is no place for yes-men around here; good ideas are desired even it means disagreeing with superiors $(\mathrm{R})$

5. Agreeing with powerful others is the best alternative in this organization

6. It is best not to rock the boat in this organization

7. Sometimes it is easier to remain quiet than to fight the system

8. Telling others what they want to hear is sometimes better than telling the truth

9. It is safer to think what you are told than to make up your own mind

10. Since I have worked for this organization, I have never seen the pay and promotions policies applied politically (R)

11. I can't remember when a person received a pay increase or promotion that was inconsistent with the published policies $(\mathrm{R})$

12. None of the raises I have received are consistent with the policies on how raises and promotions are determined

13. The stated pay and promotion policies have nothing to do with how pay raises and promotions are determined 
14. When it comes to pay raise and promotion decisions, policies are irrelevant

15. Promotions around here are not valued much because how they are determined is so political 


\section{APPENDIX F: FIGURE 1}

Conceptual Diagram Depicting Hypotheses 1a-d in Which Supervisor's BLM Moderates the Relation Between Each Dark Tetrad Trait and CWB

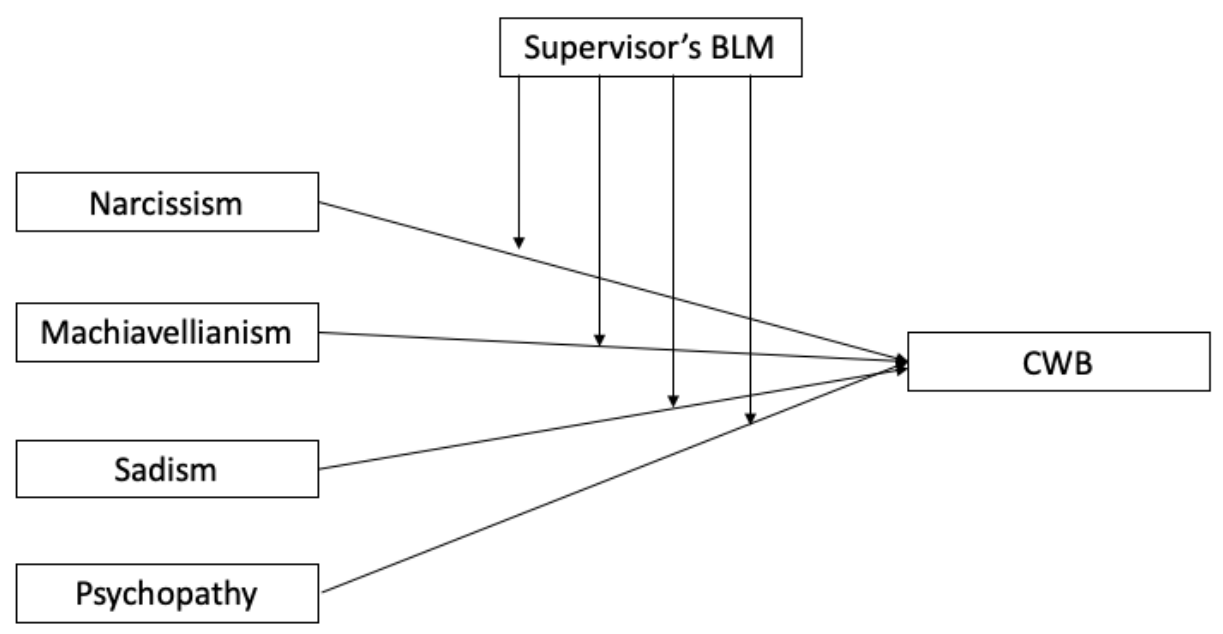




\section{APPENDIX G: FIGURE 2}

Conceptual Diagram Depicting Hypothesis 3a-d in Which Job Satisfaction Mediates the Relationships Between Each Dark Tetrad Trait and CWB

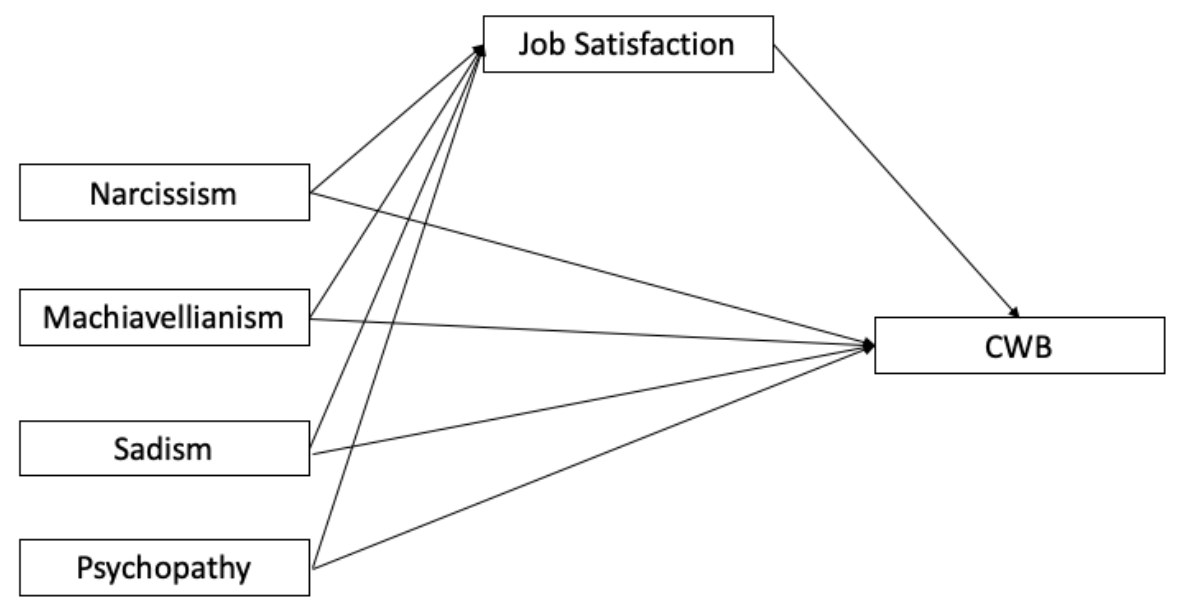




\section{APPENDIX H: FIGURE 3}

Conceptual Diagram Depicting Hypothesis 4 in Which POP Mediates the Relationship Between Sadism and CWB

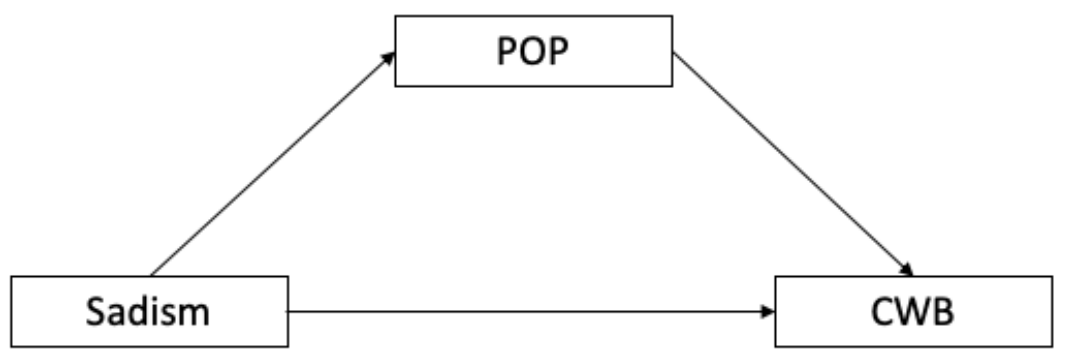


APPENDIX I: FIGURE 4

Simple Slopes for Sadism predicting CWB at -1, 0 and +1 SD of BLM

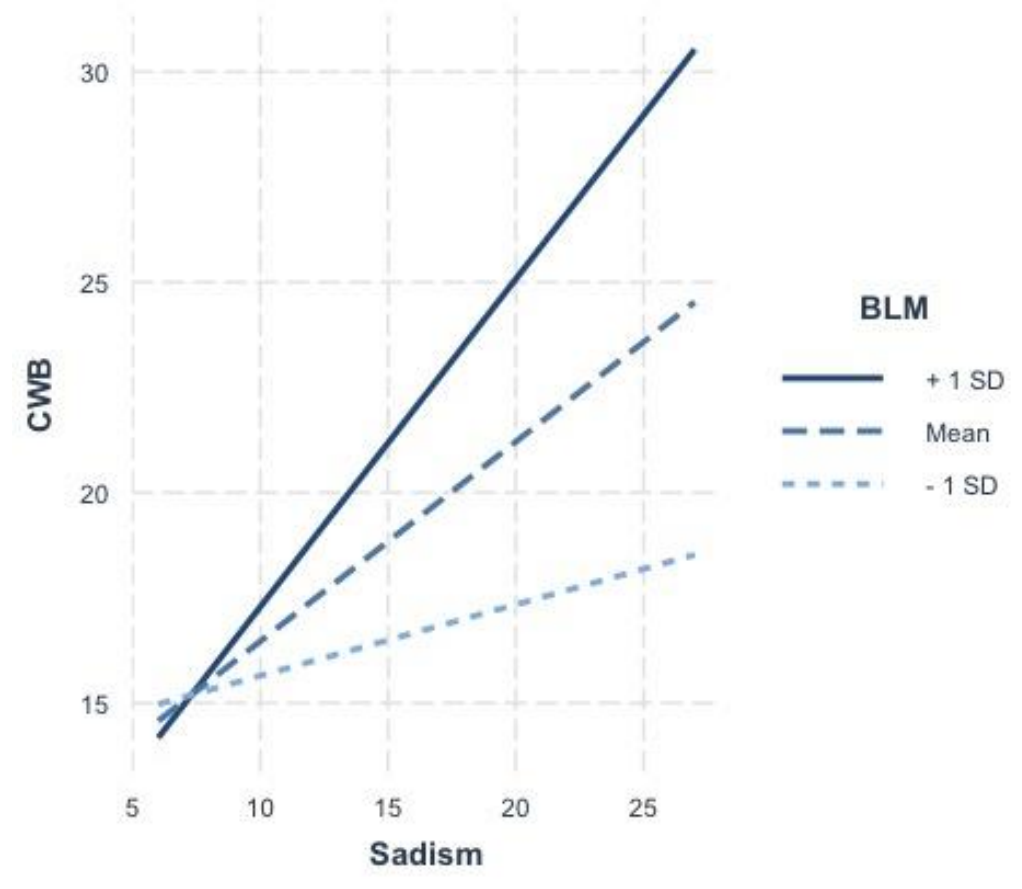




\section{APPENDIX J: TABLE 1}

\section{Sample Demographics}

\begin{tabular}{|c|c|c|}
\hline Sample Characteristic & $n$ & Percent \\
\hline \multicolumn{3}{|l|}{ Gender } \\
\hline Male & 205 & 41.8 \\
\hline Female & 259 & 52.7 \\
\hline \multicolumn{3}{|l|}{ Ethnicity } \\
\hline White & 367 & 74.7 \\
\hline Black & 45 & 9.2 \\
\hline Asian & 34 & 6.9 \\
\hline Hispanic/Latino & 9 & 1.8 \\
\hline American Indian/ & 6 & 1.2 \\
\hline \multicolumn{3}{|l|}{ Alaska Native } \\
\hline Native Hawaiian / & 1 & .2 \\
\hline \multicolumn{3}{|l|}{ Pacific Islander } \\
\hline Other/Multiracial & 2 & .4 \\
\hline \multicolumn{3}{|l|}{ Tenure } \\
\hline$<1$ year & 41 & 8.4 \\
\hline 1-3 years & 124 & 26.5 \\
\hline 3-5 years & 74 & 16.1 \\
\hline $5+$ years & 201 & 43.8 \\
\hline
\end{tabular}

Note: $n$ represents number of observed cases for each variable. Gender missing 27 cases;

Ethnicity missing 27 cases; Tenure missing 26 cases. 


\section{APPENDIX K: TABLE 2}

Means, Standard Deviations, and Correlations of Study Variables

\begin{tabular}{lccccccccccc}
\hline Variable & $n$ & $M$ & $S D$ & 1 & 2 & 3 & 4 & 5 & 6 & 7 & 8 \\
\hline $\begin{array}{l}\text { 1. Narcissism } \\
\text { 2.Machia- }\end{array}$ & 486 & 17.48 & 5.23 & $(.84)$ & & & & & & & \\
vellianism & 485 & 11.16 & 4.57 & $.17^{* *}$ & $(.87)$ & & & & & & \\
3.Psychopathy & 482 & 9.66 & 5.01 & $.35^{* *}$ & $.49^{* *}$ & $(.91)$ & & & & & \\
4. Sadism & 483 & 9.12 & 4.98 & $.37^{* *}$ & $.41^{* *}$ & $.86^{* *}$ & $(.93)$ & & & & \\
5. BLM & 488 & 13.94 & 7.1 & $.16^{* *}$ & $.58^{* *}$ & $.41^{* *}$ & $.37^{* *}$ & $(94)$ & & & \\
6. Job & & & & & & & & & & & \\
Satisfaction & 484 & 18.57 & 5.27 & $.17^{* *}$ & $-.45^{* *}$ & $-.27^{* *}$ & $-.24^{* *}$ & $-.38^{* *}$ & $(.86)$ & & \\
7. POP & 469 & 42.09 & 11.75 & 0.08 & $.62^{* *}$ & $.40^{* *}$ & $.31^{* *}$ & $.55^{* *}$ & $-.55^{* *}$ & $(.88)$ & \\
8. CWB & 486 & 16.62 & 7.03 & $.24^{* *}$ & $.45^{* *}$ & $.68^{* *}$ & $.71^{* *}$ & $.37^{* *}$ & $-.34^{* *}$ & $.38^{* *}$ & $(.90)$ \\
\hline
\end{tabular}

Note. $n$ represents number of cases observed for each variable. Cronbach alphas are reported on the main diagonal. $\mathrm{BLM}=$ bottom-line mentality $. \mathrm{POP}=$ perceptions of organizational politics . CWB $=$ counterproductive work behavior.

$*$ indicates $p<.05 . * *$ indicates $p<.01$. 


\section{APPENDIX L: TABLE 3}

Hierarchical Regression Analysis Results Using CWB as the Criterion

\begin{tabular}{lrrrrrrr}
\hline Predictor & \multicolumn{1}{c}{$b$} & \multicolumn{1}{c}{$S E$} & $\beta$ & $s r 2$ & \multicolumn{1}{c}{$t$} & $R_{2}$ & $\Delta R_{2}$ \\
\hline Step 1 & & & & & & & \\
(Intercept) & 5.73 & .88 & & & 6.49 & & \\
Narcissisma & -.05 & .04 & -.04 & -.04 & -1.14 & & \\
Machia- & .21 & .06 & .14 & .11 & 3.40 & & \\
vellianismb & & & & & & & \\
Psychopathyc & .25 & .09 & .18 & .09 & 2.82 & & \\
Sadismd & .70 & .09 & .50 & .25 & 8.08 & & \\
BLMe & .04 & .04 & .04 & .03 & 1.08 & & \\
& & & & & & .54 & $.54^{* * *}$ \\
\hline Step 2 & & & & & & & \\
(Intercept) & 10.89 & 1.98 & & & 5.50 & & \\
Narcissism & -.12 & .09 & -.09 & -.04 & -1.35 & & \\
Machia- & .10 & .13 & .07 & .02 & .77 & & \\
vellianism & & & & & & \\
Psychopathy & .58 & .25 & .41 & .07 & 2.30 & & \\
Sadism & -.01 & .26 & -.01 & .00 & -.03 & & \\
BLM & -.32 & .13 & -.32 & -.08 & -2.44 & & \\
NxBLMf & .007 & .006 & .15 & .04 & 1.18 & & \\
MxBLMg & .01 & .008 & .20 & .04 & 1.26 & & \\
PxBLMh & -.02 & .015 & -.44 & -.05 & -1.60 & & \\
SxBLMi & .04 & .015 & .75 & .09 & 2.78 & & \\
& & & & & & .55 & $.01 * *$ \\
\hline
\end{tabular}

Note. a $n=486$. $n=485$. $n=485$. d $n=483$. e BLM $=$ bottom-line mentality, $n=488$.

$\mathrm{f} \mathrm{NxBLM}=$ narcissism $* \mathrm{BLM}$ interaction term, $n=483 . \mathrm{gMxBLM}=$ Machiavellianism*BLM interaction term, $n=482$. ${ }_{\mathrm{hPxBLM}}=$ psychopathy*BLM interaction term, $n=479$. $\mathrm{S} \mathrm{SBLM}=$ sadism*BLM interaction term, $n=480$.

$*$ indicates $p<.05 . * *$ indicates $p<.01 . * * *$ indicates $p<.001$ 